Ann. Abeille, I962 5, (2), 97-I33.

\title{
ÉTUDE DE QUELQUES CONSTITUANTS DU POLLEN ( $\left.{ }^{(}\right)$
}

\author{
Harie-France HÜGLL \\ Institut de Chimie des Substances naturelles, Service du Professeur E. Lederer, \\ Gif-sur-Yvetle (Seine-et-Oise).
}

\section{SOMMAIRE.}

Dans le présent travail, nous décrivons les recherches que nous avons effectuées sur la chimie du pollen.

Dans une première partie nous rapportons les principaux résultats obtenus avec le pollen de pin (Pinus montana) responsable de la sarcoïdosa.

Nous avons ensuite examiné divers échantillons de pollens récoltés par les abeilles à la Station de Recherches sur l'Abeille et les Insectes sociaux de Bures-sur-Yvette : pollen mixte, pollen de pommier (Pirus malus), pollen de ciste (Cistus sp.). I) ans cette seconde partie, nous avons cherché à identifier les substances attractives pour les abeilles, ainsi que toutes les substances ayant pu être obtenues à l'état pur.

\section{INTRODUC'TION $\left(^{2}\right)$}

Le pollen, en tant que produit naturel très abondant, a intéressé depuis longtemps les chercheurs.

La technique du ramassage du pollen s'est beaucoup améliorée depuis quelques années. Il peut s'effectuer de deux manières :

- On laisse les abeilles butiner le pollen et l'on recueille les "pelotes " qu'elles laissent tomber dans la trappe à pollen (LouveAux, I958) .

- On peut récolter le pollen mécaniquement (ou à la main), directement, à partir des plantes.

On conçoit que ces deux modes de récoltes ne conduisent pas à de grandes quantités de pollen, si on le désire très pur.

L'intérêt du pollen est grand en agriculture, en médecine ou au point de vue purement scientifique.

(1) Le présent travail a fait l'objet d'une thìse d'ingénieur C. N. A. M. (juin 1960).

(2) Nous avons choisi pour ce bref exposé le plan suivi par Lunden (I956). 
La littérature concernant la chimie du pollen est relativement pauvre ; les travaux sont peu nombreux et, si un assez grand nombre de constituants sont isolés, peu sont identifiés. De plus, si certains se retrouvent dans de nombreuses espèces, d'autres, au contraire, semblent être spécifiques d'un pollen donné.

Nous essayerons de faire une classification rapide des principaux constituants mentionnés.

Le tableau I donne quelques valeurs relatives à la composition générale de trois pollens étudiés par NIELSEN (I955).

TABLEAU I

\begin{tabular}{|c|c|c|c|}
\hline & Zea Mays & Alnus glutinosa & Pinus monlana \\
\hline Azote $(\%) \ldots \ldots \ldots \ldots \ldots$ & 1,2 & 4,1 & 2,2 \\
\hline Protéines $(\%) \ldots \ldots \ldots \ldots \ldots$ & $26, \%$ & 25,6 & 13,8 \\
\hline Sulfates $(\%) \ldots \ldots \ldots \ldots \ldots$ & $/, 9$ & 2,4 & 3,0 \\
\hline Phosphore $(\%) \ldots \ldots \ldots \ldots \ldots$ & 0,75 & 0,42 & 0,3 \\
\hline Soufre $(\%) \ldots \ldots \ldots \ldots \ldots$ & 0,3 & 0,24 & 0,18 \\
\hline Sucres réducteurs $(\%) \ldots \ldots \ldots$ & 7,3 & 8,4 & 2,7 \\
\hline Sucres totaux $(\%) \ldots \ldots \ldots \ldots$ & 34,6 & 27,4 & 29,5 \\
\hline
\end{tabular}

\section{I. - Protéines et acides aminés :}

Les teneurs en protéines que donnent ANDERSON (I922), EILSER (I930) et WEAVER (I94I) sont très variables : II à $35 \mathrm{p}$. Ioo.

Les abeilles semblent, le plus souvent, préférer les pollens riches en protéines : elles ne butinent pas le pollen de pin, qui en est particulièrement pauvre.

La recherche et l'étude de ces substances ne commença réellement que lorsque AUCLAIR (I948) utilisa la chromatographie sur papier pour leur séparation.

Le pollen mixte renferme les acides aminés les plus répandus. Selon DE Groot (I952), seuls seraient indispensables aux abeilles les acides aminés suivants : histidine, iso-leucine, leucine, lysine, méthionine, phényl-alanine, thréonine, valine, arginine.

L'allergie que présentent certaines personnes au pollen (rhume des foins) semble être liée à la composition des protéines : I 87 plantes ont été reconnues jusqu'ici comme étant allergissantes.

AbRAmson (I947) isole par électrophorèse, des pollens de certaines espèces sauvages, des fractions protéiniques incolores qui constituent la partie essentielle des extraits actifs ; ces protéines sont de bas poids moléculaires $(M=5000)$; elles sont liées à des sucres (pentoses). Ce sont l'artéfoline, la trifoline, et la prasétine, dont la composition n'est pas encore connue. A ces protéines peut être fixé un pigment : 1 'isorhamnétine (voir les pigments).

De même, STone (r947) isole par dialyse une fraction de bas poids moléculaire possédant $50 \mathrm{p}$. Ioo de l'activité allergissante : cette fraction contient des sucres liés à un polypeptide.

Les extractions faites par l'eau ou des solutions salines conduisent à des mélanges extrêmement complexes : acides aminés libres, sucres, polypeptides ou protéines, liés à des sucres ou des pigments. 
Presque tous les travaux effectués sur les fractions protéiniques ont été faits sur des pollens ayant un grand pouvoir allergissant ; on ne connait rien sur la composition des protéines des autres espèces.

VIRTANEN (I955) a fait des expériences comparées entre la composition de la feuille et celle du pollen et il a pu dire que le pollen contient plus de proline et d'acide pipécolique que les feuilles, et moins de citrulline. La synthèse de la proline se ferait à partir de l'acide glutamique et celle de l'acide pipécolique à partir de la lysine. I1 isole aussi des acides aminés moins courants comme l'homosérine, l'acide $\gamma$-aminobutyrique, l'acide $\gamma$-amino-adipique et des amines (asparagine, glutamine) ; ses recherches ont porté sur une dizaine de plantes différentes.

Sosa-BouRdouil (I954) signale aussi la présence d'acides nucléiques: $\mathrm{r}, 35 \mathrm{p}$. Ioo calculé sur la substance sèche ; celle de l'acide désoxyribonucléique n'a pu être mise en évidence.

\section{II. - Sucres}

Ils sont abondants et semblent être d'un intérêt secondaire pour la nutrition des abeilles. Il sont en général liés aux protéines.

Von Planta (I885) signale la présence d'amidon et de saccharose. Ensuite ANDERson (I922) isole des pentoses et des sucres réducteurs. La présence de ces sucres réducteurs est d'ailleurs contestée par SOSA-BARDOUIL (I954) : ils n'existeraient pas initialement sous cette forme mais sous celle d'holosides et de sucres polymérisés. En effet, on ne trouve pas de sucres réducteurs dans le pollen récolté mécaniquement, mais uniquement dans le pollen récolté par les abeilles qui cimentent leurs pelotes par du miel ou du nectar riche en glucose et autres sucres réducteurs.

KHUN (1949) mit en évidence la présence du lactose : c'était la première fois que ce sucre était trouvé dans le règne végétal.

Puis Sanero-Ueno (I954) identifia, grâce à la chromatographie sur papier, le fructose, le saccharose, le raffinose et le stachyose :

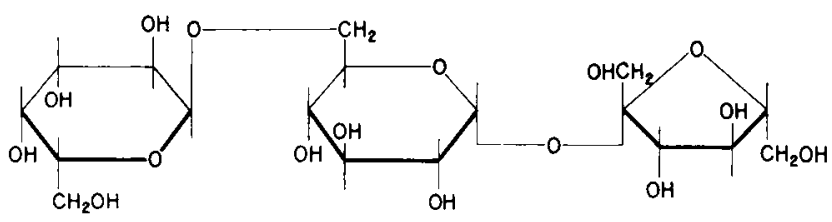

Raffinose

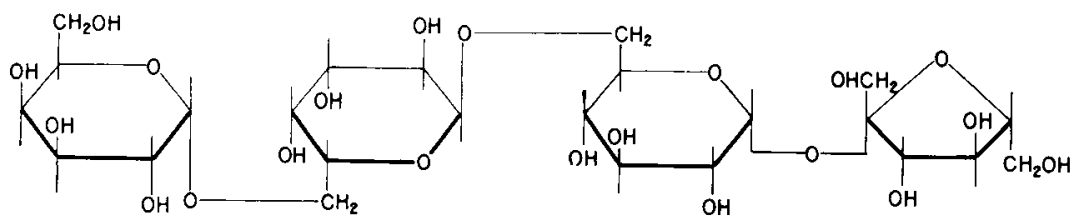

Stachyose

VoN Eulter (I945) a isolé, à côté des acides nucléiques, du ribose et du désoxyribose. 


\section{IIr. - Lipides, acides gras, stérols, alcools, hydrocarbures}

Suivant les différents auteurs, ANDERSON (I922), ELSER (I94I), VIRTANEN (I955) et Sosa-Bardouir. (I952), la teneur des pollens en lipides varie de I à 20 p. Ioo. En général, ils considèrent que leur présence est très importante pour la nourriture des abeilles. Une grande variété de composés ont été isolés et identifiés à partir des extraits éthérés ou alcooliques de pollens. Après saponification de ces extraits on obtient :

- une fraction non saponifable : dans laquelle on peut isoler :

- des hydrocarbures saturés : tricosane, SosA (1952) heptacosane et nonacosane, ANDERSON (I923).

- des hydrocarbures insaturés : $\mathrm{C}_{20} \mathrm{H}_{40}$ et $\mathrm{C}_{34} \mathrm{H}_{58}$ (SPADA, I958).

- des alcools : ils sont en grand nombre, saturés et mono-hydroxylés : on trouve en particulier des alcools de formule brute, $\mathrm{C}_{15} \mathrm{H}_{32} \mathrm{O}$ SosA (I952), $\mathrm{C}_{27} \mathrm{H}_{56} \mathrm{O}$ et $\mathrm{C}_{25} \mathrm{H}_{52} \mathrm{O}$ SPADA ( $195^{8}$ ), qui ne sont pas encore identifiés. Nir.SOr (I957) isole un mélange de $n$-tétracosanol, $n$-hexacosanol et les paraffines correspondantes, mélange qui fut résolu grâce à la spectrographie de masse. MARIELIA (I952) trouve dans des variétés d'Artemisia, des alcools à haut poids moléculaire qu'il n'a pu identifier.

- des stérols : aucune identification précise n'a encore été faite. VoN PLANTA (I885) crut isoler du "cholestérol ", puis ANDERSON (I922) obtint deux stérols insaturés, monohydroxylés, lévogyres, dont les analyses élémentaires correspondent aux formules brutes $\mathrm{C}_{26} \mathrm{H}_{43} \mathrm{OH}$ et $\mathrm{C}_{21} \mathrm{H}_{35} \mathrm{OH}$.

- une fraction acide : le seul acide ayant pu être reconnu jusqu'à présent est l'acide palmitique : on le trouve sous forme de palmitate de phytostérol. ANIDERSN (1922) décrit un mélange d'acides gras non identifiés; Sosa (I952) isole un acide en $\mathrm{C}_{11} \mathrm{H}_{31} \mathrm{CO}_{2} \mathrm{H}$ isomère de l'acide laurique et un acide ramifié $\mathrm{C}_{22} \mathrm{H}_{45} \mathrm{CO}_{2} \mathrm{H}$. Après saponification et extraction par le réactif $\mathrm{T}$ de GiraRd, SOSA-BOURuour. (I954) et Nirssor (I957) ont isolé des fractions cétoniques : grâce à la spectrographie de masse Nirsson a identifié la $n$-tri, n-penta, $n$-hepta et $n$-nonacosanone ; SosA n'a pas identifié les produits composant cette fraction.

\section{IV. - Vitamines et hormones}

I es pollens sont très riches en vitamines du groupe B et pauvres en vitamines lipo-solubles. ANDERson (I922) isole de l'inositol puis HAydaK (I938) trouve de la vitamine $\mathrm{E}$ et signale un fait intéressant : la gelée royale, unique nourriture de la reine, ne contient pas de vitamine $\mathrm{E}_{\text {. }}$ Le même auteur isole ensuite de la vitamine $B_{1}$ puis de la vitamine $B_{2}$; PEARson (I942) étudie plus spécialement l'acide panthoténique : il émet l'hypothèse que les abeilles synthétisent cette vitamine durant l'élaboration de la gelée royale. Vivino (I944), le premier, établit une liste des vitamines présentes dans différents pollens (pissenlit, trèfle, pommier, bouton d'or, aster et prunier). Il démontra que la richesse en vitamines varie au cours de l'année : durant l'été la niacine est très abondante et entre juin et fin septembre 1'acide panthoténique atteint son maximum de concentration.

SEKINE (I942) a pu prouver, par des dosages biologiques faits sur des rats nourris au pollen de pin, que celui-ci était exempt de vitamines $A, B$ et $D$. (Les vitamines $A$ et $\mathrm{D}$ existent sous la forme de provitamines dans le règne végétal). Puis Weygand (I950) isola de 1'acide folique et de l'acide ascorbique. 
A la suite de Vivivo (I944), Ridi (I950) et NiLsson (I957) établirent une liste des principales vitamines présentes dans différents pollens.

Quelques hormones ont été mises en évidence dans le pollen : en particulier l'œstrone isolée du pollen de palmier dattier par RIDI (I950).

On signale, de même, la présence de substances de croissance (test $P$ isum positif); un des facteurs responsables pourrait être la 2 -hydroxy-5-hydroxyméthyl pyridine.

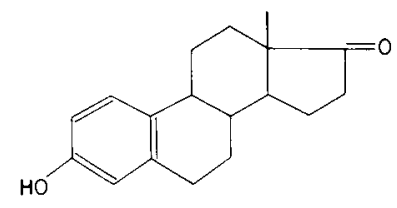

Oestrone<smiles>O=Cc1ccc(O)nc1</smiles>

$2-$ hydroxy -5 hydroxymethyl pyridine

V. - Enzymes, coenzymes.

Les multiples activités biochimiques du pollen en ont fait un champ d'action très riche pour l'étude des réactions enzymaticues.

ELSER (I930) signale la présence d'amylase, saccharase, catalase ; SosA-BocRDouIr, (I939) étudie l'activité de la saccharase dans divers pollens.

Des études furent entreprises sur la respiration du pollen et sur la fermentation alcoolique qu'il peut subir : les résultats ont montré que cette fermentation est identique à celle provoquée par la levure.

On signale aussi la présence des déshydrogénases des acides lactique et succininique, de systèmes cytochrome-oxydases (respiration) OKONUKI, (I942) et VON EULER (I949).

L'activité enzymatique est maxima au moment de la germination et les variations peuvent être considérables, même dans une même espèce.

Récemment Nakamura (195I) a étudié l'action des phosphatases.

\section{VI. - Pigments}

On peat séparer dans les récoltes obtenues à la trappe à pollen, les différents constituants, grâce à leur couleur; les colorations que présentent les pelotes faites par les abeilles vont du jaune pâle au vert, avec toutes les gammes d'orangés et de bruns. Les pigments isolés appartiennent à deux grandes classes :

- celle des flavonö̈des: HEYL (IgI $)$ isole un glucoside d'isorhamnétol : il émet 1'hypothèse que cette substance joue probablement un rôle dans le processus de fertilisation. Effectivement KUHN (I944) a montré que cet éther méthylique du quercétol, isolé du pollen de Crocus, pouvait être un facteur déterminant du sexe des cellules reproductrices. Deux dérivés du quercétol ont été isolés : 1'un se trouve dans les fleurs à long style, l'autre uniquement dans celles à style court :<smiles>O=c1c(O)c(-c2ccc(O)c(O)c2)oc2cc(O)cc(O)c12</smiles>

Quercétol<smiles>COc1cc(-c2oc3cc(O)cc(O)c3c(=O)c2O)ccc1O</smiles>

Isorhamnétot 
— celle des caroténoïdes : ont été isolés<smiles>CC1=CCCC(C)(C)C1/C=C\C(C)=C/C=C\C(C)=C/C=C\C=C(C)\C=C/C1=C(C)CCCC1(C)C</smiles>

$\alpha$-carotène<smiles>Cc1ccccc(C)cccc(C)c(C)cccc(C)ccc1</smiles>

Lycopene<smiles>CC(C)=CC/C=C(C)\C=C/CC/C=C(C)\C=C/C=C(C)\C=C/C1C(I)=CC(O)CC1(C)C</smiles><smiles>CC(C)=CC=CC(C)=CC=C(C)C(C)=CC=CC(=O)O</smiles>

Vivino (I944) les isola dans les proportions suivantes:

- 50 à $\mathrm{I} 50 \mu \mathrm{g} / \mathrm{g}$ pour les carotènes ;

- I40 à $400 \mu \mathrm{g} / \mathrm{g}$ pour les xantophylles.

VON EULER (I945) fit remarquer que les insectes récoltent généralement des pollens contenant des caroténoïdes, tandis que les pollens transportés par le vent sont riches en flavonoïdes.

Jusqu'à présent il n'est pas fait mention d'autres classes de pigments et en particulier ni de chlorophylles, ni d'anthocyanes.

\section{VII. - Activités biologiques du pollen. Pollénines}

Le pollen de Pinus montana provoque la sarcoïdose, affection voisine de la tuberculose par ses symptômes. Cummings (I958) pensait avoir décelé dans le pollen de ce pin deux des constituants que l'on trouve dans les fractions toxiques du bacille de Koch (voir la partie dı travail personnel consacré à cette espèce).

Le pollen a une activité bactériostatique certaine : il détruit une partie de la flore intestinale de la souris (en particulier Escherichia coli, Chauvin (r952)). Une nourriture à base de pollen semblerait provoquer des tumeurs également chez la souris, ROBINSON (I948).

Les pollénines ont été étudiées par ZETZSCHE (I93I) ; on groupe sous ce nom des substances mal définies qui se trouvent dans la membrane de nombreux pollens et dans les spores de Ptéridophytes. Il a isolé en particulier une sporo-pollénine de 
formule $\mathrm{C}_{90} \mathrm{H}_{138} \mathrm{O}_{22}$; cette substance entrerait dans la composition de l'exine (partie la plus externe de la membrane entourant le grain de pollen, elle est essentiellement formée de cutine). Ces substances sont extraites dans des conditions assez brutales (après traitement par $\mathrm{SO}_{4} \mathrm{H}_{2}$ à $75 \mathrm{p}$. IOo), il se pourrait qu'elles constituent un artefact. La proportion des pollénines est différente suivant que l'on s'adresse aux Gymnospermes (Pinus sylvestris 20 p. IOO) ou aux Angiospermes (Coryllus avellana 7,3 p. Ioo) la proportion de cellulose étant respectivement de 2,2 et I, I p. Ioo dans ces deux groupes.

\section{VIII. - Constituants divers}

VON PlaNTA (I885) signala la présence de globuline, peptone, xanthine, guanine, hypoxanthine : ces résultats ne furent ni infirmés ni confirmés.

\section{IX. - Constituants minéraux}

Ils ont été déterminés par : Von PLANTA (I885), EIsER (r930), Vivino (I944), RIDI (I950) et NIELSEN (I957) ; ce sont essentiellement du potassium, du magnésium, du calcium, du cuivre (en quantité importante) du fer, du silicium, du phosphore 'sous forme protidique ou phytinique et sous forme minérale), du soufre et du chlore.

\section{ÉTUDE DU POLIEN DE PIN (Pinus montana)}

Cummings (I958) a montré que le pollen de Pinus montana a la particularité de provoquer une sarcoïdose --- nécrose pulmonaire analogue à celle provoquée par le bacille de Koch - spontanée chez l'homme et expérimentale chez la souris. Il a recherché l'agent chimique responsable de cette altération pulmonaire. Il pense avoir identifié, dans le pollen, en question, des acides gras à longues chaînes, $\alpha$-ramifiés, $\beta$-hydrolylés, analogues aux acides mycoliques que l'on isole de Mycobacterium tuberculosis, ainsi que l'acide $\alpha, z$-diaminopimélique (DAP) que l'on trouve également dans les Mycobactéries. Cet acide aminé est d'ailleurs spécifique des bactéries et n'a, jusqu'à présent, jamais été rencontré dans d'autres organismes. Or, des bacilles tuberculeux virulents, on peut isoler des Cires $D$ dont la toxicité est bien établie, et qui sont des esters d'acides mycoliques avec un polysaccharide et un peptide renfermant le DAP (ASSELINFAAU I95I).

C'est dans le but d'obtenir des fractions toxiques analogues à celles que l'on isole du bacille tuberculeux (phosphatides, "cord-factor ", cires $D$ ), et pour vérifier les indications de Cummras que nous avons entrepris l'étude du pollen de Pinus montana en suivant les techniques utilisées pour le bacille de Koch.

\section{RÉSULTATS}

\section{A. - Extraction par l'alcool-éther (I : I)}

ANDERSON (I930) a montré que chez le bacille tuberculeux, la fraction de l'extrait alcool-éther insoluble dans l'acétone bouillante correspond au phosphatide doué de propriétés nécrosantes pour les cellules épithéliales. 
I. - Sur la première partie nous avons procédé à une extraction par l'acétone bouillante; nous avons obtenu:

a) un précipité cristallin, qui se trouve être du saccharose. Il n'y avait pas de précipité blanc lipidique dans l'acétone bouillante : il ne semble donc pas y avoir de phosphatides à haut point de fusion dans le pollen.

Dans le cas où un phosphatide à bas point de fusion a été entraîné, on peut le séparer sous forme d'huile restant au fond du récipient, en réchauffant sans agiter le précipité et sas eaux mères ; dans le cas du pollen tout repasse en solution : il n'y a donc pas de phosphatide à bas point de fusion.

b) une fraction soluble à chaud (qui, par refroidissement, laisse précipiter du saccharose), et une fraction soluble à température ordinaire qui contient des sucres, du glycérol et vraisemblablement du xylose ou ses produits de condensation. Il n'y a pas de phosphatides dans cette fraction.

II. - Nous avons séparé la seconde partie de l'extrait alcool-éther par un mélange éther-eau; nous avons pu ainsi éliminer la fraction osidique trop importante. Nous obtenons :

a) une fraction hydrosoluble dans laquelle, après hydrolyse, nous avons essayé de mettre en évidence l'acide $\alpha, \varepsilon$-diaminopimélique : nous n'en avons pas trouvé.

b) une fraction éthérosoluble qui pourrait renfermer, éventuellement, les acides mycoliques. Pour les séparer des acides gras infétieurs on précipite la solution éthérée par un grand volume de méthanol : dans le cas du bacille tuberculeux, le précipité renfermerait les acides mycoliques et leurs esters. Nous obtenons effectivement un précipité que nous avons chromatographié sur silicate ; la fraction principale est éluée par le benzène ; or, dans une telle chromatographie les acides mycoliques sont élués par un mélange éther-méthanol ou éther-acide acétique : il ne semble donc pas y avoir d'acides mycoliques.

La fraction éluée au benzène est un ester $\mathrm{C}_{40} \mathrm{H}_{80} \mathrm{O}_{2}, \mathrm{~F}^{\prime} 69-70^{\circ}$. Nous n'avons pu pousser plus loin l'étude de ce produit, car il se trouve en quantité relativement faible et nous ne disposions plus de pollen de pin.

\section{B. - Extraction par le chloroforme}

Elle se fait sur le résidu laissé par l'extrait alcool-éther. Dans le cas du bacille de Koch, on traite cet extrait (comme l'extrait alcool-éther) par l'acétone bouillante ; on obtient alors:

a) une fraction insoluble à chaud: ce sont les cires I) ;

b) une fraction soluble à chaud, mais qui précipite à froid : ce sont les cires C dans lesquelles on isole par chromatographie sur silicate (élution chloroforme-méthanol 4 : I) un produit extrêmement toxique : le "Cord-factor » ou dimycolate de tréhalose, Noll (I956), 'T. GENDRE (I956)

c) une fraction soluble à froid : elle correspond aux cires B.

I'extrait chloroformique du pollen traité de la même façon donne une très importante fraction insoluble dans l'acétone bouillante ( $42 \mathrm{p}$. roo de l'extrait ). Par refroidissement précipite en petite quantité un produit (I9 p. Ioo de l'extrait) qui semble identique à celui isolé de l'insoluble à chaud : spectre IR et point de fusion identiques. Étant donné la petite quantité de substance, nous n'avons étudié que la 
fraction insoluble dans l'acétone à chaud. Cette fraction est un ester $\mathrm{C}_{46} \mathrm{H}_{92} \mathrm{O}_{2} \pm \mathrm{CH}_{2}$, qui se présente sous forme de cristaux fondant à $74-76^{\circ}$.

Après saponification, nous obtenons :

- une partie acide : il s'agit en fait d'un mélange d'acides : la chromatographie en phase gazeuse de leurs esters méthyliques a séparé l'acide palmitique, l'acide stéarique, 1'acide arachidique et l'acide béhénique.

- une partie insaponifiable : l'alcool obtenu répond à la formule brute $\mathrm{C}_{\mathbf{2 6}} \mathrm{H}_{\mathbf{5 4}} \mathrm{O}$ et fond à $78-79^{\circ}$.

Dans la littérature il est mentionné un alcool cérylique, monohydroxylé, non ramifié, en $\mathrm{C}_{26}, \mathrm{~F} 79^{\circ}$; pour vérifier que nous avions bien affaire à cet alcool nous avons préparé un alcool cérylique à partir d'un acide mycolique de souche humaine ; il est en effet, connu que par pyrolyse cet acide donne uniquement de l'acide héxacosanoïque (acide $\mathrm{C}_{26} \mathrm{H}_{50} \mathrm{O}_{2}$ : ASSELINEAU, I95I), il suffit ensuite de réduire l'acide selon le schéma suivant:

$$
\mathrm{R}-\underset{\mathrm{HO}}{\mathrm{CH}}-\underset{\mathrm{C}_{24} \mathrm{H}_{49}}{\mathrm{CH}}-\mathrm{CO}_{2} \mathrm{H} \underset{300^{\circ}}{\stackrel{\text { pyrolyse }}{\rightarrow}} \mathrm{R}-\mathrm{CHO}+\mathrm{C}_{26} \mathrm{H}_{52} \mathrm{O}_{2} \frac{\text { réduction }}{\mathrm{AlLiH}_{4}} \mathrm{C}_{26} \mathrm{H}_{54} \mathrm{O}
$$

Le point de fusion du mélange de l'alcool synthétique et de l'alcool naturel ne présente pas d'abaissement.

Pour avoir une preuve supplémentaire nous avons fait un même dérivé coloré sur les deux alcools : ces dérivés azobenzoylés sont identiques: les analyses élémentaires coïncident et il n'y a pas d'abaissement du point de fusion du mélange des deux substances.

L'ester de départ est donc un mélange de palmitate, de stéarate, d'arachidate et de béhénate de céryle.

\section{Conclusions}

Nous n'avons pu, dans le pollen de Pimus montana, isoler les constituants qui, dans le bacille de Koch, sont considérés comme responsables de la tuberculose et que Cummings semblait avoir identifiés dans ce pollen.

\section{DESCRIPTION DES EXPÉRIENCES}

\section{A. - Extraction par l'alcool-éther (I : I)}

L'extrait total s'élève à ı $\mathrm{p}$. Ioo du poids du pollen.

I. - Traitement d'une partie de l'extrait par l'acétone bouillante

Nous obtenons, après filtration à chaud :

a) un précipité blanc: qui représente 20 p. Ioo de l'extrait alcool-éther; il est cristallin : F I 70 ${ }_{1} 7^{\circ},(\alpha)_{1}^{18}+64^{\circ}$. Il a une saveur sucrée, est soluble dans l'eau et réduit la liqueur de Fehling, après hydroloyse par l'acide chlorhydrique.

La chromatographie sur papier Whatman no i montre :

I tache à la hauteur du saccharose, avant hydrolyse,

I tache à la hauteur du glucose, après hydrolyse,

I tache à la hauteur du fructose, après hydrolyse.

b) une fraction soluble à chaud : il y a formation d'un précipité par refroidissement. 


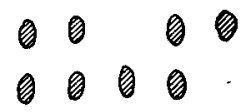

FIG. I. - Chromatographie descendante sur papitr.

Pollen de pin : extrait alcool-éther I : I ;

fractions insolubles dans l'acétone ;

I : fraction insoluble dans l'acétone bouillante avant hydrolyse ;

II : saccharose ;

III : fraction insoluble dans l'acétone à froid avant hydrolyse ;

IV : saccharose, glucose, fructose ;

$V:$ fraction insoluble dans l'acétone à chaud après hydrolyse ;

VI : fructose ;

VII : fraction insoluble dans l'acétone à froid après hydrolyse ;

VIII : glucose;

solvant de développement : butanol-acide acétique-eau ;

révélation : phtalate acide d'aniline;

papier Whatman $n^{\circ} \mathrm{I}$.

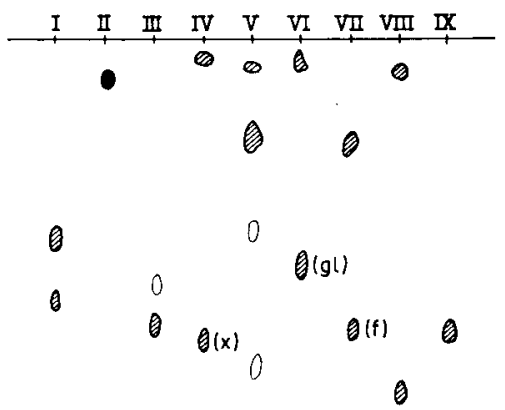

\section{0}

FIG. 2. - Chromatographie descendante sur pateer.

Pollen de pin : extrait alcool-éther I : I ;

fraction soluble dans l'acétone ;

I : mannose, galactose ;

II : inositol, glycérol ;

III : fraction êtudiée avant hydrolyse acide ;

IV : glucosamine, $\mathrm{HCl}$; xylose (x) ;

$\mathrm{V}$ : fraction étudiée après hydrolyse acide ;

VI : xylotriose, glucose (gl) ;

VII : xylobiose, fructose (f);

VIII : saccharose, ribose ;

IX : arabinose ;

solvant de développement : iso-propanol-acide acétique-eau;

révélation : acide périodique/benzidine ;

papier Arches 304. 


\section{Etude du précipité insoluble à froid :}

Il correspond à peu près à ıo p. Ioo de l'extrait. Il est formé de cristaux blancs semblables à ceux obtenus dans l'insoluble à chaud : F $186^{\circ}(\alpha)_{18}^{\mathbf{D}}=+65,5^{\circ}$ : il s'agit bien de saccharose identifié avant et après hydrolyse (fig. I).

Analyse élémentaire : $\mathrm{C}_{\mathbf{1 2}} \mathrm{H}_{\mathbf{2 2}} \mathrm{O}_{11}$, trouvé en pourcentage : $\mathrm{C}_{42,32} \quad \mathrm{H} 6,60$ calculé en pourcentage : C 42, IO H 6,48 .

Les eaux mères, fraction soluble à froid : correspondent à $68 \mathrm{p}$. 100 de l'extrait.

Analyse élémentaire : $\mathrm{C} 43,33$ p. ıоo $\mathrm{H} 8$, 01 p. 100 P 0,045 p. 100.

Cette fraction est très oxygénée : nous avons fait un dosage à l'anthrone selon Radin (1955) ce dosage est positif et indique la présence de 64 p. 100 de sucres (le calcul a été fait par rapport au glucose).

Une hydrolyse dans l'acide chlorydrique $(4 \mathrm{~N})$, à $105^{\circ}$, durant 6 heures, fournit 7 p. Ioo d'hydrosoluble. Par chromatographie descendante dans les solvants, I, III, IV (i), nous avons obtenu, après révélation à l'acide périodique (GORDON, 1956).

I tache à la hauteur du xylobiose ;

I tache à la hauteur du xylotriose

I tache à la hauteur du glycérol.

(fig. 2) ;

\section{2. - Séparation du reste de l'extrait par un mélange eau-éther:} obtenu :

Cette séparation a été faite pour éliminer la fraction osidique trop importante; nous avons

a) Un hydrosoluble : soit $5^{8} \mathrm{p}$. 100 de l'extrait. Nous avons recherché sur cette fraction la présence de DAP par chromatographies sur Whatman $n^{0} \mathbf{I}$; nous avons fait ces chromatographies simultanément :

sur le pollen brut (avant et après hydrolyse).

sur l'hydrosoluble (avant et après hydrolyse).

(les hydrolyses sont faites dans l'acide chlorydrique $(6 \mathrm{~N})$ à $105^{\circ}$ durant 8 heures.) Ni la révélation à la ninhydrine (BERRY, 1949), ni la réaction de WORK (1955), ne donnent de résultats positifs : il ne semble pas y avoir d'acide $\alpha, \varepsilon \cdot$ diaminopimélique.

\section{b) Un éthérosoluble:}

Qui correspond a $4^{2}$ p. Ioo de l'extrait. Le précipité ainsi formé, $348 \mathrm{mg}$, soit $1 \mathrm{I}$ p. 100 de l'extrait, est chromatographié sur $\mathrm{I} 3 \mathrm{~g}$ de silicate de magnésium; le volume de solvant employé pour chayue élution est de $30 \mathrm{~cm}^{3}$ :

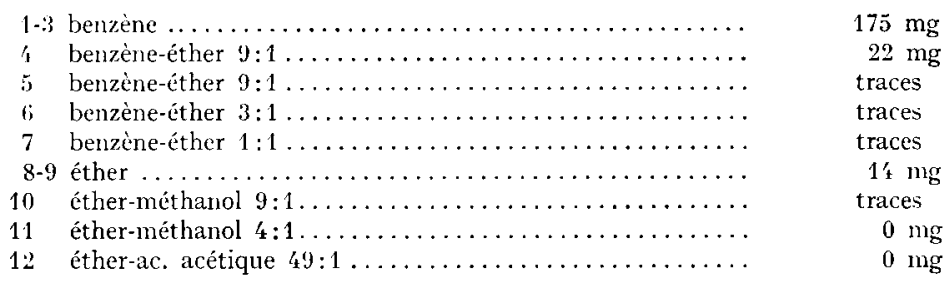

Etude des fractions $\mathrm{I}-3$ : après cristallisation dans le benzène, on obtient des cristaux $\mathrm{F} 69-72^{\circ}$, $(\alpha)_{\mathrm{D}}^{18}=\mathrm{o}$ (chloroforme).

Analyse élémentaire : $\mathrm{C}_{20} \mathrm{H}_{40} \mathrm{O}$;

trouvé en pourcentage : $\mathrm{C} 8 \mathrm{r}, 2 \mathrm{O}$ H $\mathrm{H}_{3}, 65$;

calculé en pourcentage : $\mathrm{C} 8 \mathrm{r}, 00 \mathrm{H} \mathrm{r} 3,60$.

Le spectre IR présente une forte bande vers I $75^{\circ} \mathrm{cm}^{-1}$ : bande ester ou cétone (fig. 3).

essai de formation d'une oxime : à $20 \mathrm{mg}$ de produit on ajoute $100 \mathrm{mg}$ de chlorhydrate d'hydroxylamine, $150 \mathrm{mg}$ d'acétate de sodium et $10 \mathrm{~cm}^{3}$ de benzène, on laisse 24 heures au reflux, on épuise à l'éther; cet éther, après lavage par l'eau jusqu'à $\mathrm{pH}$ neutre, est séché sur sulfate de sodium puis évaporé et la substance est cristallisée dans l'alcool : son point de fusion est identique à celui du produit de départ et elle ne contient pas d'azote. Nous avons donc affaire à un ester dont la formule brute pourrait être $\mathrm{C}_{40} \mathrm{H}_{80} \mathrm{O}_{2}$.

(1) Les systèmes de solvants utilisés pour les chromatographies sont :

Solvant I : butanol/acide acétique/eau $4 / \mathrm{I} / \mathrm{I}$;

Solvant II : butanol/acide formique/eau $75 / 15 / 10$;

Solvant III : isopopanol/acide acétique/eau $6 / 3 / \mathbf{I}$;

Solvant IV : phénol/eau $80 \mathrm{~g}$ dans $20 \mathrm{~cm}^{3}$ eau ; 
essai de saponification : I $50 \mathrm{mg}$ sont dissous dans $10 \mathrm{~cm}^{3}$ de potasse méthanolique $(2 \mathrm{~N})$ et laissés 8 heures au reflux ; après séparation de la fraction insaponifiable (59 p. 100) et de la fraction acide (30 p. I0o), nous avons chromatographié $90 \mathrm{mg}$ d'insaponifiable sur $\mathrm{r}, 8 \mathrm{~g}$ d'alumine : le produit reste absorbé sur la colonne.

\section{B. --. Extraction par le chloroforme}

I.'extrait équivaut à o,9 p. too du poid sec.

Par l'extraction à l'acétone bouillante on obtient :

- une fraction insoluble à chaud ;

- une fraction insoluble à froid.

Ces deux fractions ont le même spectre IR et un point de fusion identicue.

\section{I. - Etude de la fraction insoluble dans l'acétone bouillante:}

Cette fraction est filtrée à chaud, l'insoluble est dissous dans le chloroforme et reprécipité par l'acétone : nous avons alors obtenu des plaquettes blanches qui, après recristallisation dans le benzène fondent à $75^{\circ}$. La totalité des cristaux, soit $33^{\circ} \mathrm{mg}$, a été filtrée sur $7 \mathrm{~g}$ de silicate et éluée par fractions de $25 \mathrm{~cm}^{3}$.
1 éther de jétrole-benzènc 1:
$203 \mathrm{mg}$
2 ether de pétrole-benzène $1: 1 \ldots \ldots \ldots \ldots \ldots \ldots \ldots \ldots \ldots$
$189 \mathrm{mg}$

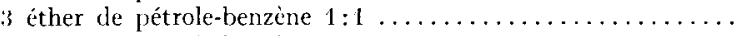
$28 \mathrm{mg}$
\& éther de pétrole-benzène $1: 1 \ldots \ldots \ldots \ldots \ldots \ldots \ldots \ldots$ traces

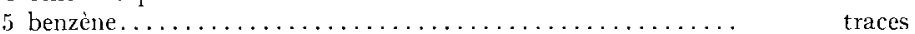
i) henzène-ether $(1: 1 \ldots \ldots \ldots \ldots \ldots \ldots \ldots \ldots \ldots \ldots \ldots \ldots \ldots \ldots$

Les deux premières fractions sont recristallisées dans le chloroforme et donnent des cristaux qui fondent à $74^{-} 7^{\circ}$.

Analyse élémentaire : $\quad \mathrm{C}_{23} \mathrm{H}_{\mathbf{4 6}} \mathrm{O}$

trouvé en pourcentage : $\mathrm{C}_{21,54} \quad \mathrm{H}_{13,76}$;

calculé en pourcentage : $\mathrm{C} 81,58$ II 53,69 .

L'équivalent moléculaire est de 339,93, mais la masse moléculaire, calculée par le Rast, est de 700 , ce cqui conduit à la formule brute $\mathrm{C}_{\mathbf{4 6}} \mathrm{I}_{\mathbf{9 2}} \mathrm{O}_{\mathbf{2}}$. Le spectre $\mathrm{IR}$ a une forte bande ester à I $750 \mathrm{~cm}^{-\mathrm{t}}$ (fig. 4).

\section{Saponification:}

too $\mathrm{mg}$ de ces cristaux sont dissous dans $5 \mathrm{~cm}^{3}$ de benzène, on y ajoute $5 \mathrm{~cm}^{3}$ de potasse méthal. nolique et on laisse 15 heures à reflux ; après extraction par l'éther, on obtient :

- 6r $m g$ d'une parlie acide qui, après cristallisation dans le méthanol, fond à $64-64,5^{\circ}$.

Analyse élémentaire : $\mathrm{C}_{22} \mathrm{H}_{44} \mathrm{O}_{2}$

trouvé en pourcentage: $\mathrm{C}_{77,7.3}$ II I 2,98 ;

calculé en pourcentage : $\mathrm{C} 77,58$ II $\mathrm{I}_{3}, 02$.

L'équivalent moléculaire, calculé par titration, est de 339, ce qui correspondrait à un acide en $\mathrm{C}_{22} \mathrm{H}_{44} \mathrm{O}_{2}$.

Nous avons alors méthylé cette fraction acide par le diazométhane dans l'éther ; après évaporation de l'éther et cristallisation dans le méthanol, nous avons obtenu un produit dont le point de fusion n'est pas net, $\mathrm{F} 34-39^{\circ}$; l'analyse élémentaire est correcte pour l'ester méthylique de l'acide $\mathrm{C}_{19} \mathrm{H}_{38} \mathrm{O}_{2}$.

Analyse élémentaire: $\mathrm{C}_{20} \mathrm{H}_{40} \mathrm{O}_{2}$

trouvé en pourcentage : $\mathrm{C} 76,34$ Il 12,76 ;

calculé en pourcentage : $\mathrm{C} 76,86$ H I 2,86 .

Il est évident qu'il s'agit d'un mélange : nous avons alors injecté la substance en solution dans l'éther, dans un appareil à chromatographie gaz-liquide et il est apparu, par comparaison avec des témoins, que nous avions bien affaire à un mélange de quatre acides (fig. 5) : acide palmitique $\mathrm{C}_{16} \mathrm{H}_{32} \mathrm{O}_{2}$, acide stéariçue $\mathrm{C}_{18} \mathrm{H}_{36} \mathrm{O}_{2}$, acide arachidique $\mathrm{C}_{20} \mathrm{H}_{40} \mathrm{O}_{2}$, acide béhénique $\mathrm{C}_{22} \mathrm{H}_{44} \mathrm{O}_{2}$. 

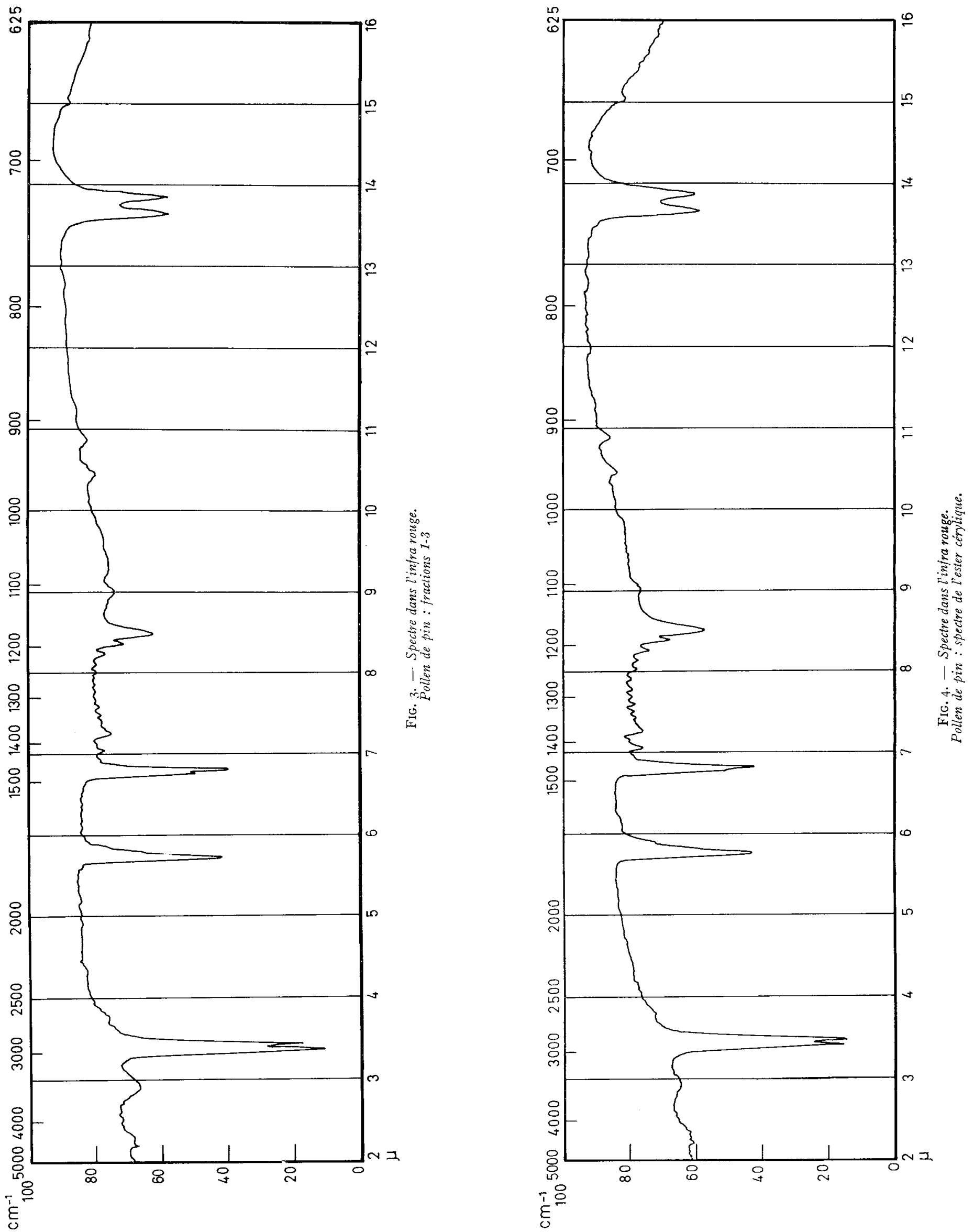
- Une partie insaponifiable : après cristallisation dans le benzène, nous obtenons $38 \mathrm{mg}$ de cristaux blancs, $\mathbf{F}:{ }_{7} 8-79^{\circ}$.

Analyse élémentaire : $\mathrm{C}_{20} \mathrm{H}_{54} \mathrm{O}$

trouvé en pourcentage : $\mathrm{C}_{8 \mathrm{I}, 78}$

calculé en pourcentage : C 81,60

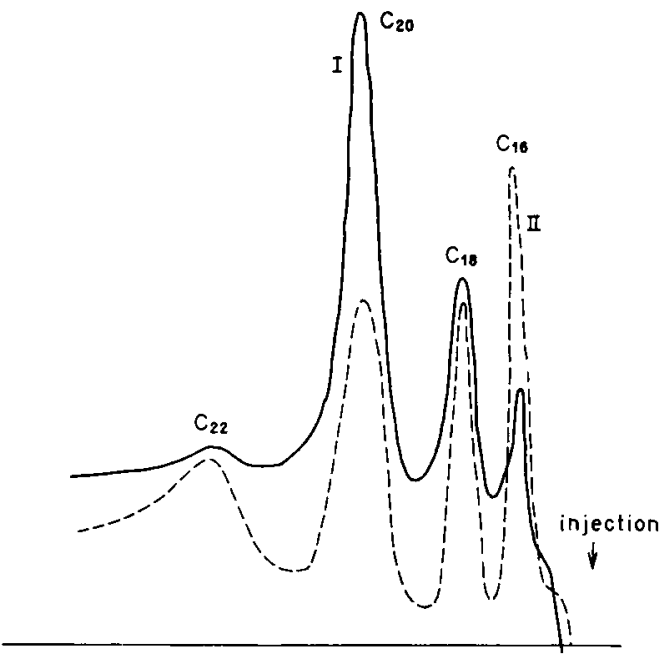

I'IG. 5. - Chromatographie en phase gazeuse des esters méthyliques des acides inonocarboxyliques $\mathrm{C}_{16} \mathrm{C}_{18} \mathrm{C}_{20} \mathrm{C}_{22}$

Phase stationnaire : silicone ;

température : $25^{\circ}$;

pression à l'entrée : $240 \mathrm{~mm}$;

pression à la sortie : $15 \mathrm{~mm}$;

débit d'azote : $\mathrm{r}, 2 \mathrm{l} / \mathrm{h}$;

sensibilité : $92 \mathrm{~mA}$;

appareil utilisé : Griffin et George ;

I : esters méthyliques inconnus;

II : esters méthyliques témoins.

\section{Préparation de l'alcool synthétique:}

- pyrolyse : I g d'acide mycolique de souche Brévannes donne, par pyrolyse entre 270 et $300^{\circ}$, $200 \mathrm{mg}$ d'acide hexacosanoïque que l'on cristallise dans le benzène, F $83-87^{\circ}$.

Analyse élémentaire : $\mathrm{C}_{26} \mathrm{H}_{52} \mathrm{O}_{2}$ trouvé en pourcentage : $\mathrm{C} 78,54$ calculé en pourcentage : $\mathrm{C} 78,52$

II 12,99 ;

$\mathrm{H} \mathrm{I}_{3}, 2 \mathrm{I}$.

-. réduction de l'acide en alcool : 50 $\mathrm{mg}$ d'acide sont dissous dans $20 \mathrm{~cm}^{3}$ d'éther, cette solution est versée dans $310 \mathrm{mg}$ d'hydrure double d'aluminium et de lithium, en suspension dans $10 \mathrm{~cm}^{3}$ d'éther. On agite mécaniquement la solution durant 48 heures. Après destruction de l'hydrure en excès par l'acide sulfurique, on extrait l'alcool par l'éther ; la purification du produit se fait par chromatographic sur alumine : l'alcool est élué par un mélange benzène-éther $9: 1$, il est ensuite cristallisé dans le chloroforme; on obtient des cristaux qui fondent à $77-79^{\circ}$.

Analyse élémentaire : $\mathrm{C}_{26} \mathrm{H}_{54} \mathrm{O}$

trouvé en pourcentage : $(8 \mathrm{I}, \mathrm{I} 6$

calculé en pourcentage : C 81,60

II I 3,95 ;

$\mathrm{H}$ i4,22.

Il n'y a pas d'abaissement du point de fusion du mélange des deux alcools.

- formation d'un dérivé azobenzoylé sur chacun des deux alcools : $12 \mathrm{mg}$ d'alcool naturel sont dissous dans $\mathrm{I} \mathrm{cm}^{3}$ de benzène, on y ajoute $0,75 \mathrm{~cm}^{3}$ de pyridine anhydre et $\mathrm{I} 2 \mathrm{mg}$ de chlorure d'azo- 
benzoyle ; on laisse 36 heures à température ordinaire ; on extrait à l'éther et on lave successivement par deux fois $5 \mathrm{~cm}^{3}$ de carbonate de sodium à $5 \mathrm{p}$. 1oo, une fois par $5 \mathrm{~cm}^{3}$ d'eau ; on sèche sur sulfate de sodium et après évaporation de l'éther, on cristallise dans l'éther de pétrole-benzène ; les cristaux sont ensuite chromatographiés sur silicate, la fraction éluée à l'éther de pétrole-benzène $(4: \mathrm{I})$ est cristallisée dans le benzène-éther de pétrole et fond à $82-85^{\circ}$.

Nous avons fait le même dérivé sur $30 \mathrm{mg}$ d'acide synthétique, il fond à $82-85^{\circ}$.

Le mélange des deux dérivés ne présente pas d'abaissement du point de fusion $\mathrm{F} 82-85^{\circ}$.

Les analyses élémentaires sont correctes pour les valeurs du carbone et de l'hydrogène, légèrement faibles pour la teneur en azote :

- calculé pour $\mathrm{C}_{38} \mathrm{H}_{62} \mathrm{O}_{2} \mathrm{~N}_{2} \quad \mathrm{C}_{79,27}$ p. $100 \quad$ II 10,58 p. $100 \quad \mathrm{~N}_{4,74}$ p. 100 ;

- trouvé pour le dérivé de l'alcool de synthèse :

C 79,09 p. 100 H II,47 p. I00 N 3,82 p. 100;

-.- trouvé pour le dérivé de l'alcool naturel :

C 79,13 p. I00 H i r,34 p. 100 N 3,88 p. гоo.

\section{F́TUDE D'UN POLLEN MIXTE.}

Le mélange de pollen mis à notre disposition était composé de pollen de légumineuses (Trèlle), de papavéracées (Coquelicot), de rosacées (Pommier) et de quelques espèces forestières (Orme).

Le but principal de ce travail a été d'isoler la fraction attirant les abeilles. Les expériences ont été effectuées de la manière suivante :

Les substances étudiées sont placées dans de petits godets de verre et disposées sur une étagère située à une certaine distance de la ruche (cette ruche se trouve dans une serre maintenue à température constante). Après quelque temps (celui qui est nécessaire aux éclaireuses pour alerter les butineuses), les abeilles viennent puiser d'abord à la source la plus riche, puis ensuite aux endroits qui les attirent le moins ; il suffit d'étudier la detısité de population autour de différents récipients pour savoir quelle est la substance qui a l'influence prédominante. Les tests ont toujours été faits en présence de substances témoins : pollen pur et poudre de cellulose qui sert à faire les dilutions.

La grande facilité avec laquelle nous pouvions nous procurer ce pollen en quantité importante, nous l'avait fait choisir comme premier matériel, avant d'aborder l'étude du pollen pur, assez difficile à se procurer en quantités appréciables.

\section{RÉsultats}

\section{A. - Extrait éthéré}

Il est obtenu par épuisement du pollen à température ordinaire. Il se révèle aussi attractif que le pollen brut.

I. - Isolement de la fraction responsable de l'activité biologique.

Après saponification l'activité biologique se retrouve toute entière dans la fraction insaponifiable.

Différents essais de purification de cette fraction (distillation, chromatographie) ont eu des résultats négatifs. En définitive, la meilleure purification paraît être celle que l'on obtient par chromatographie sur silicate : la fraction éluée par un mélange benzène-éther 4 :I possède une importante activité biologique. 
Une purification purement physique d'une partie de cette élution nous a fourni une substance très attractive, mais en faible quantité : une chromatographie de ce produit sur acide silicique n'a donné aucun résultat positif.

La fraction insaponifiable a un test de Liebermann positif (coloration blen-vert caractéristique des stérols, JAVILLIER (I949). Nous avons essayé de séparer les stérols en les extrayant au moyen de leur combinaison avec la digitonine, PESEz et Porrier (I954 a) : les seules substances à former les digitonides sont les stérols $3, \beta$-aminés ou hydroxylés et ayant une double liaison en 5 (plus quelques cas très spéciaux), et les $\alpha$ - ou $\beta$-naphtols (et quelques alcools terpéniques). Après traitement et séparation des constituants nous obtenons :

a) Une fraction ne formant pas de digitonide. - elle est peu importante et possède un très fort pouvoir attracteur sur les abeilles. C'est un stéroïde ou mélange de stéroïdes (la réaction de Liebermann est positive) qui fond à $\mathrm{I} 23-\mathrm{I} 32^{\circ}$. On peut penser qu'il s'agit de stéroïdes non extractibles par la digitonine ou que la formation du digitonide n'a pas été complète.

b) Une fraction stérolique. - Que nous avons essayé de purifier par cristallisarion dans le méthanol : cette fraction nous a fourni :

$\alpha-u n$ précipité : qui fond à $84-85^{\circ}$, a un pouvoir rotatoire de $(\alpha)_{\mathbf{b}}^{18}=-29^{\circ}$ et dont l'analyse élémentaire correspond à $\mathrm{C}_{50} \mathrm{H}_{30} \mathrm{O}_{2}$.

$\beta$ - une fraction soluble que nous avons divisée en deux parties:

la première partie, chromatographiée sur silicate nous a fourni, à l'élution benzène-chloroforme $95: 5$, une fraction qui, après cristallisation dans l'alcool, laisse déposer des cristat1x F $95^{-} \mathrm{ro2}^{\circ},(x)_{\mathrm{D}}^{18}=+22^{\circ}$, et dont la formule brute est $\mathrm{C}_{27} \mathrm{H}_{48} \mathrm{O}_{2}$.

Les eaux mères de ces cristaux, chromatographiées sur acide silicique désactivé ont donné denx fractions :

- la première est éluée à l'éther de pétrole-benzène $4: \mathrm{I}$; après sublimation, nous obtenons un produit fondant à $80-82^{\circ},(\alpha){ }_{\mathbf{D}}^{18}=+52^{\circ}$, dont la formule brute est $\mathrm{C}_{29} \mathrm{H}_{48} \mathrm{O}_{2}$; ce stérol forme un acétate dont l'analyse élémentaire correspond à $\mathrm{C}_{50} \mathrm{H}_{31} \mathrm{O}_{3}$ et qui ne cristallise pas.

- la seconde fraction est éluée par un mélange éther de pétrole-benzène I : I ; c'est une substance très hygroscopique.

la seconde partie de cette fraction stérolique est acétylée puis chromatographiée sur silicate: les substances que nous obtenons de cette manière sont très mal définies et il est impossible de les séparer étant donné le pen de produit dont nous disposions.

\section{II. - Isolement de la praction cétonique:}

Après saponification, on extrait au moyen de réactif de GIRARD (1930), une fraction qui, après chromatographie sur alumine, a fourni entre autre :

- aux élutions benzène-éther $7: 3:$ une cétone de formule brute $\mathrm{C}_{34} \mathrm{H}_{38} \mathrm{O}_{2}, \mathrm{~F} 74^{\circ}$.

- aux élutions benzène-éther $I: I$ : de la palmitone.

\section{B. - Extrait alcoolique}

Il est obtenu par épuisement du résidu laissé par les extractions à l'éther.

Nous avons entrepris l'étude de la première fraction éluée, par du chloroformeméthanol $95: 5$, d'une colonne de silicate ; après séparation à l'éther nous avons :

Annales de l'Abeille. - 1962. 
- une fraction éthérosoluble qui contient du 24-méthylène-cholestérol ;

- une fraction insoluble dans l'éther, soluble dans le butanol, insaponifiable et dont la combustion est incomplète : il pouvait s'agir du phytomélane, selon C. et J. Asseinead (I957), mais ni le spectre IR, ni l'analyse ne concordent. Nous avons soumis cettre fraction à diverses hydrolyses.

- une hydrolyse très brutale nous a permis de constater, par chromatographie sur papier, que la substance ne contenait pas d'acides aminés et que les sucres présents s'étaient vraisemblablement condensés.

- une hydrolyse plus douce permet d'obtenir un chromatogramme où existent trois taches révélables au phtalate acide d'aniline (PAR'TRIDGE, I949) à la hauteur du xylobiose, du mannose ou de l'arabinose (qui ont le même $\mathrm{R}_{F}$ ). Par révélation à l'acide périodique on fait apparaître une tache à la hauteur du glycérol.

\section{Conclusions}

La fraction qui présente un test de butinage positif semble être une fraction stérolique; en tout cas, elle accompagne une fraction riche en stérols ou stéroïdes.

Le 24-méthylène-cholestérol, isolé pour la première fois dans le règne végétal a été identifié dans ce mélange de pollens.

\section{DESCRIPTION DES EXPERIENCES}

\section{A. - Extrait éthéré:}

Il représente 3,5 p. I00 en poids de pollen pur. Il est aussi attractif que le pollen brut.

A) - Essai de séparation de la fraction ayant un test de butinage positif:

Nous avons saponifié $39,8 \mathrm{~g}$ d'extrait (dissous dans $20 \mathrm{~cm}^{3}$ de benzène) par $40 \mathrm{~cm}^{3}$ de potasse méthanolique $(2 \mathrm{~N})$; après être restée 4 heures à reflux, la solution a été extraite à l'éther ; cet éthérosoluble a été lavé à l'eau, puis séché : il a foumi $26,7 \mathrm{~g}$ d'insaponifiable (soit $66 \mathrm{p}$. Ioo de l'extrait). L'hydrosoluble acidifié par l'acide sulfurique et extrait à l'éther, donne I3, I g de partie acide.

\section{I. -- Une partie de l'insaponifiable:}

Soit I $\mathrm{g}$, a été chromatographiée sur $30 \mathrm{~g}$ d'alumine ; le résultat est peu satisfaisant, le produit s'élue difficilement avec un mélange éther-méthanol 4: I; $83 \mathrm{mg}$ sont ainsi isolés qui ont un test biologique positif. La réaction de Liebermann est positive : cette coloration bleue-verte témoignant de la présence de stérols est un des traits caractéristiques de cette fraction.

\section{2. - Le reste de l'insaponifiable:}

Soit $25,3 \mathrm{~g}$ est dissous dans $10 \mathrm{~cm}^{3}$ de benzène et saponifié, une seconde fois, par $25 \mathrm{~cm}^{3}$ de potasse méthanolicjue $(2 \mathrm{~N})$ durant 3 heures au reflux. Après les extractions ordinaires, nous avons isolé:

$6,6 \mathrm{~g}$ de partie acide ;

I 6,7 $\mathrm{g}$ d'insaponifiable.

Nous avons alors soumis la partie insaponifiable aux essais suivants :

a) distillation : $\mathrm{1}, 5 \mathrm{~g}$ dans un tube à boules sous $0, \mathrm{I} \mathrm{mm}$; nous recueillons trois fractions :

la première entre i 60 et $180^{\circ}$;

la seconde entre 180 et $200^{\circ}$;

la troisième entre 200 et $250^{\circ}$.

Aux essais biologiques, ces trois fractions ne montrent plus aucune activité.

b) chromatographie de $2,7 \mathrm{~g}$ sur $125 \mathrm{~g}$ de silicate (soit 60 fois le poids du produit) : on élue avec un mélange éther-méthanol $4:$ : $220 \mathrm{mg}$ de produit fortement attracteur qui est purifié par 
passage sur une colonne de $20 \mathrm{~g}$ d'acide silicique : on obtient $103 \mathrm{~g}$ d'une substance attractive dont les spectres dans l'ultra violet et le visible ne présentent aucune absorption caractéristique.

c) chromatographie sur silicate, en prenant comme poids d'absorbant to fois le poids du produit : les séparations sont meilleures et cette chromatographie est reproductible.

I 2,5 g d'insaponifiable sont filtrés sur $125 \mathrm{~g}$ de silicate; les élutions sont de $300 \mathrm{~cm}^{3}$ :

\begin{tabular}{|c|c|c|c|}
\hline $1-3$ & benzìne .............. & $7,712 \mathrm{gr}$ & cire jaune \\
\hline $4-8$ & benzène-éther $95: 5 \ldots \ldots \ldots \ldots \ldots \ldots$ & $2,378 \mathrm{~g}$ & cire orange \\
\hline 9 & benzène-éther $4: 1 \ldots \ldots \ldots \ldots \ldots \ldots$ & $0,612 \mathrm{~g}$ & cire rouge \\
\hline $10-1^{\prime} t$ & benzène-éther & $1,439 \mathrm{~g}$ & cire rouge \\
\hline $15-18$ & éther.......... & $0,430 \mathrm{~g}$ & cire rouge \\
\hline $19-20$ & éther-méthanol $4: 1$. & $0,283 \mathrm{gr}$ & cire jaune \\
\hline 21 & éther-acide acétique $19: 1 \ldots \ldots \ldots$ & $0,008 \mathrm{~g}$ & cire jaune \\
\hline
\end{tabular}

TABIEAU 2

Tests fonctionnels et biologiques.

\begin{tabular}{|c|c|c|c|c|c|}
\hline & $\begin{array}{l}\text { Hydroxamique } \\
\text { FEIGL }\left(195^{\prime}\right)\end{array}$ & LIERIERMANN & $\begin{array}{c}\text { LEGAL, PESEZ } \\
\text { et POIRIER } \\
(1954 b)\end{array}$ & $\begin{array}{c}\text { DNP } \\
\text { dinitrophényl } \\
\text { hydrazones } \\
\text { CIIERONIS (1957) }\end{array}$ & $\begin{array}{c}\text { Test } \\
\text { de butinage }\end{array}$ \\
\hline $1-3$ & + pour ester & - & - & - & 0 \\
\hline $4-8$ & t pour ester & - & - & - - & ++ \\
\hline 9 & + pour ester & + & $\ldots$ & -- & ++++ \\
\hline $10-1 / 4$ & + pour ester & + & - & - & $+++t$ \\
\hline $15-18$ & + jour ester & brun-vert & $\ldots$ & - & $+t$ \\
\hline $19-20$ & + pour phénol & jaune & - & + & + \\
\hline 21 & + pour phénol & - & -. & -- & + \\
\hline
\end{tabular}

\section{Fitude des fractions 9 -14.}

Ces fractions ont une activité biologicjue ; elles représentent au total 1,961 g. L'ensemble de ces fractions est soumis à deux traitements :

a) Traitement physique : $360 \mathrm{mg}$ sont dissous à chaud dans de l'éther de pétrole; à froid il y a séparation d'un précipité blanc ne possédant aucune activité biologique. La fraction soluble qui est très attractive est dissoute à chaud dans l'alcool absolu; scule la fraction soluble dans l'alcool absolu à froid attire les abeilles; la partie insoluble qui se dépose est un solide blanc amorphe. On sépare un précipité inactif et une fraction soluble ayant une notable activité, lorsqu'on dissout dans de l'alcool à $80^{\circ}$ la fraction soluble de l'alcool absolu. On obtient ainsi $79 \mathrm{mg}$ d'une substance cireuse jaune qui ne possède pas de spectre dans le visible. Son spectre IR montre une bande OH ou NII vers $3000 \mathrm{~cm}^{-1}$ et une bande cétone ou ester à $1750 \mathrm{~cm}^{-1}$. Il n'y a pas de formation de dinitro-phénylhydrazone ; il y a peu de chance pour que cette substance soit une cétone. Nous avons chromatographié cette cire sur $4 \mathrm{~g}$ d'acide silicique ; les élutions sont de $20 \mathrm{~cm}^{3}$.

\begin{tabular}{|c|c|c|}
\hline $1-2$ & benzène $\ldots \ldots \ldots \ldots \ldots \ldots \ldots \ldots \ldots \ldots \ldots \ldots$ & 1't ngg \\
\hline 3 & benzène éther $95: 5$ & 0 \\
\hline $1-6$ & benzène-éther $\mathbf{t}: 1 \ldots$ & 2 mg \\
\hline 7 & 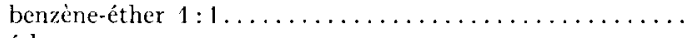 & 2 \\
\hline 8 & 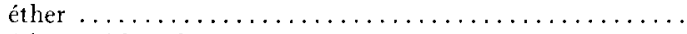 & 5 \\
\hline $10-12$ & éther méthanol $4: 1 \ldots \ldots \ldots \ldots \ldots \ldots \ldots \ldots \ldots \ldots \ldots \ldots$ & \\
\hline
\end{tabular}

Les tests biologiques sont fortement positifs pour les fractions $4^{-6}$ et ro- 2.

b) Traitement chimique : essai de formation d'une digitonide :

On verse $\mathrm{I}, 6 \mathrm{~g}$ de substance dans une solution de digitonine $\left(5 \mathrm{~g} / 450 \mathrm{~cm}^{3} \mathrm{~d}\right.$ 'alcool à $\left.90^{\circ}\right)$, on laisse deux jours à température ordinaire. On essore le précipité formé (précipité 1 ), on le lave à l'alcool et à l'éther (solution I). On redissout le précipité I dans la pyridine et on sépare en partie insoluble 
(précipité 2) et partie soluble (solution 2) en ajoutant une grande quantité d'éther à la solution pyridinique.

- le précipité 2 est la digitonine régénérée;

- la solution I est la fraction ne formant pas de digitonide;

- la solution 2 est composée de stérols.

$\alpha$. Fraction ne formant pas de digitonide : on concentre la solution et l'on précipite le réactif qui aurait pu rester dans l'éther. Une fois purifiée cettc fraction qui fond à $123^{-1} 3^{\circ}$, possède un $(\alpha)_{\mathbf{b}}^{\mathbf{1 8}}=-35,7^{\circ}\left(\mathrm{CHCl}_{3}\right)$, est envoyée aux essais biologiques : elle se révèle très attractive. La réaction de Liebermann est positive (coloration verte). Une séparation sur chromatoplaque dans le benzèneacétate d'éthyle 9: I (fig. 6) et une révélation au chlorure d'antimoine montrent une seule tache situéc à la hauteur du cholésterol ou du 24-méthylène-cholestérol.

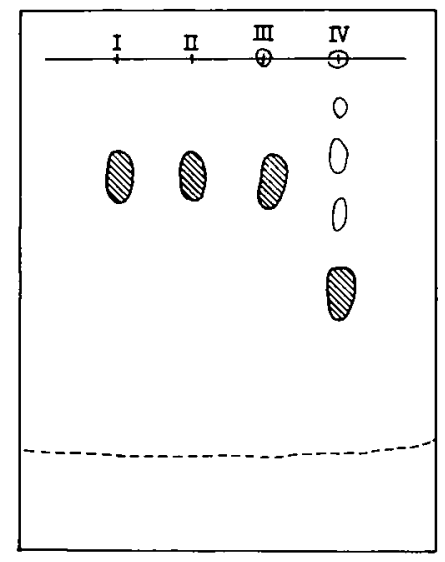

Fig. 6. - Chromaloplaque de stérols.

Support : amidon-acide silicique ;

solvant de développement : benzène-acétate d'éthyle $9: 1$;

révélation: $\mathrm{Cl}_{3} \mathrm{Sb} / \mathrm{CHCl}_{3}$;

I: produit inconnu ;

II : produit inconnu;

III : cholestérol ;

IV : ergostérol.

Le spectre IR (fait dans le bromure de potassium) présente les bandes méthylènes à 6 , I et II $3 \mu$. I $6 \mathrm{mg}$ de cette substance (dissous dans $3 \mathrm{~cm}^{3}$ de pyridine) sont acétylés par $2,5 \mathrm{~cm}^{3}$ d'anhydride acétique durant une nuit à $37^{\circ}$; après extraction à l'éther, lavages à l'acide chlorydique $(2 \mathrm{~N})$ et au carbonate de sodium ( 5 p. I oo), puis évaporation de la solution éthérée, nous obtenons une substance que nous avons distillée à $150^{\circ}$ sous $0,1 \mathrm{~mm}$. Le produit recristallisé dans le méthanol, nous fournit des cristaux blancs qui fondent à $122-123^{\circ}$.

B. Fraction stírolique : La solution 2 évaporée est séchée au dessicateur. On obtient $970 \mathrm{mg}$ de stérols bruts: $F$ 59-7 $0^{\circ}$, Liebermann positif. Par cristallisation dans le méthanol, nous obtenons :

- un précipité blanc (I $5 \circ \mathrm{mg}$ ) qui, une fois recristallisé dans le méthanol fond à $84-85^{\circ}$ et a un $(\alpha) \underset{1}{18}=-29^{\circ}\left(\mathrm{CHCl}_{3}\right)$ Liebermann négatif.

Analyse élémentaire : $\mathrm{C}_{30} \mathrm{H}_{50} \mathrm{O}_{2}$ trouvé en pourcentage : $\mathrm{C} 8 \mathrm{I}, 56$ calculé en pourcentage : C 81,39

$$
\begin{gathered}
\text { H I } 0,86 ; \\
\text { H I I }, 38 .
\end{gathered}
$$

$20 \mathrm{mg}$ sont acétylés $\left(2 \mathrm{~cm}^{3}\right.$ de pyridine $/ 2 \mathrm{~cm}^{3}$ d'anhydride acétique, une nuit à $37^{\circ}$; après extraction de l'éther et lavage de cette solution éthérée au carbonate et à l'eau on amène à sec) et chromatographiés sur $400 \mathrm{mg}$ de silicate; avec le benzène on élue $9 \mathrm{mg}$ d'un produit que l'on recristallise dans le méthanol et qui fond entre 55 et $6 \mathbf{1}^{\circ}$. parties :

- une fraction soluble dans le méthanol $(820 \mathrm{mg})$ : nous avons divisé cette fraction en deux 
$\alpha$. I70 $\mathrm{mg}$ sont chromatographiés sur $3 \mathrm{~g}$ de silicate; les élutions sont de $10 \mathrm{~cm}^{3}$ :

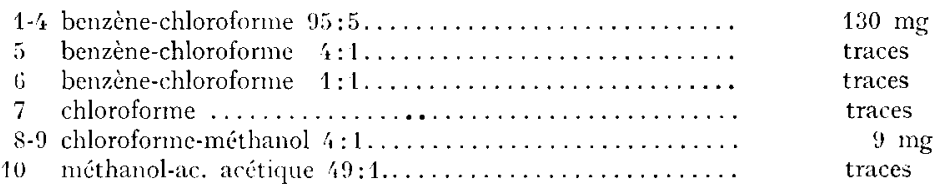

La première fraction a un Liebermann positif. On cristallise dans le méthanol : on obtient : zo mg

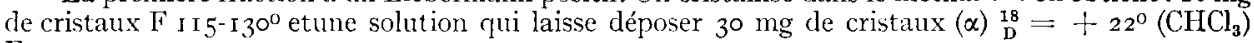
F $95^{-102^{0}}$.
Analyse élémentaire : $\mathrm{C}_{27} \mathrm{H}_{48} \mathrm{O}_{2}$
trouvé en pourcentage : $(: 80,00$
calculé en pourcentage : C 80,14
II II, 25;
H I I, 96 .

Les eaux mères de ces différents cristaux, soit $80 \mathrm{mg}$ sont chromatographiées sur $3 \mathrm{~g}$ d'acide silicique contenant 30 p. roo d'eau; les élutions sont de $5 \mathrm{~cm}^{3}$ :

\begin{tabular}{|c|c|c|}
\hline & éther de pétrole-benzène ....... & 0 \\
\hline $2-5$ & 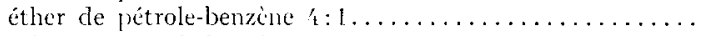 & $35 \mathrm{mg}$ \\
\hline i) & éther de jétrole-benzéme $\{: 1 \ldots \ldots \ldots \ldots \ldots \ldots \ldots \ldots$ & traces \\
\hline $7-9$ & éther de pétrole-benż̀ne $1: 1 \ldots \ldots \ldots \ldots \ldots \ldots \ldots \ldots$ & \\
\hline 10 & benzene .................. & 1) \\
\hline 11 & benzène-éther $9: 1 \ldots$ & \\
\hline 12 & éther $\ldots \ldots \ldots \ldots \ldots \ldots \ldots \ldots \ldots \ldots$ & \\
\hline 13 & méthanol-acide arétique $19: 1 \ldots$ & \\
\hline
\end{tabular}

fractions 2-5: cristallisées dans le méthanol : il y a formation de longues aiguilles incolores $\mathrm{F}_{95}-\mathrm{IO}_{2}^{\circ}$ (fig. 7). Après sublination à $I_{4} 0^{\circ}$ sous $0,02 \mathrm{~mm}$, on obtient un produit $\mathrm{F} 80-82^{\circ}(\alpha)_{10}^{18}=+52^{\circ}$ $(\mathrm{CHCl})_{3}$.

Analyse élémentaire : $\mathrm{C}_{29} \mathrm{H}_{48} \mathrm{O}_{2}$

trouvé en pourcentage: $(: 8 \mathrm{I}, 28$ II II,, 6 ;

calculé en pourcentage : $(: 8,25$ II ir,29.

sur $20 \mathrm{mg}$ de ce stérol, on fait un acétate (dans I $\mathrm{cm}^{3}$ d'anhydride acétique, 2 heures ì reflux) ; après les extractions ordinaires et chromatographie sur roo mg de silicate (élution benzène) on a une substance qui ne cristallise pas (8 $\mathrm{mg})$.
Analyse élémentaire : $\mathrm{C}_{31} \mathrm{II}_{50} \mathrm{O}_{3}$ trouvé en pourcentage : $\mathrm{C} 78,79$
calculé en pourcentage : $\mathrm{C} 79, \mathrm{I} 0$
H I0,95;
II J $0,7 \mathrm{I}$.

fractions 7-9 :après recristallisation dans le méthanol cette substance fond entre i 22 et $140^{\circ}$. Après sublimation à i $60^{\circ}$ sous $0,02 \mathrm{~nm}$ on obticnt une substance hygroscopique F Io 2 à I I 7 - I $28^{\circ}$ (après recristallisation sur plaque $\mathrm{F}$ I I $7^{-}$- $\left.28^{\circ}\right)$.

ß. $650 \mathrm{mg}$ sont acétylés par $15 \mathrm{~cm}^{3}$ d'anhydride acétique dans Io $\mathrm{cm}^{3}$ de pyridine à $37^{\circ}$ durant la nuit; après extractions, on chromatographie le produit sur $10 \mathrm{~g}$ de silicate; élutions de $30 \mathrm{~cm}^{3}$. Nous espérions séparer plus facilement les stérols sous forme d'acétate.

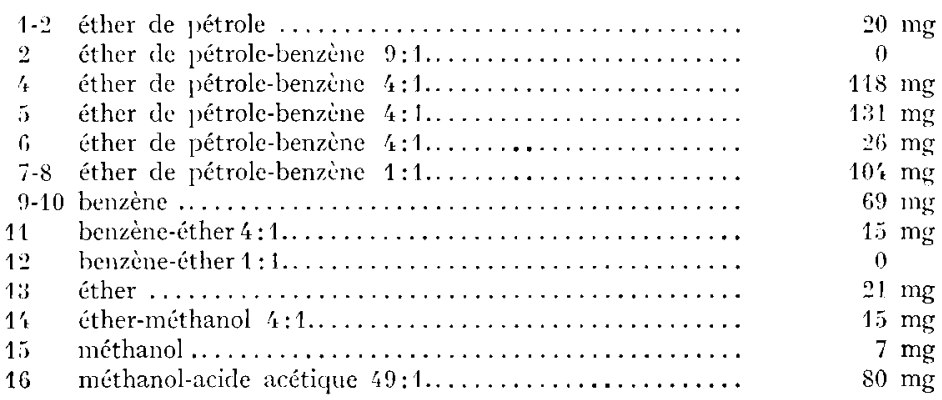


fraction 4 : après deux cristallisations dans l'alcool absolu, les cristaux fondent à $65^{-82^{\circ}}$ et après une autre cristallisation à $70-80^{\circ}$.

fraction 5 : après deux cristallisations dans l'alcool, on obtient des plaquettes $\mathrm{F} 70-85^{\circ}$; après une troisième cristallisation elles fondent à $74^{-} 80^{\circ}$.

fractions $7-8$ : on obtient, après une cristallisation dans l'alcool, des cristaux F $62-120^{\circ}$ qui, après une seconde cristallisation, fondent à $69-74^{\circ}$.

Nous avons donc affaire à un mélange fort complexe (les points de fusion restent très mauvais) ; nous arrivons à des quantités trop faibles pour pouvoir poursuivre les séparations. Nous avons essayé de résoudre ces mélanges sur chromatoplaques selon la technique de DEMoLE (I958), avec des stérols libres ou leurs combinaisons avec les réactifs de Liebermann, mais ils ne sont pas séparés (hexaneacétate d'éthyle à diverses concentrations et toluène saturé de propylène glycol).

\section{B). - Essai de séparation d'une fraction cétonique:}

Nous avons dissous $24,6 \mathrm{~g}$ d'extrait éthéré dans $50 \mathrm{~cm}^{3}$ de benzène à chaud, ajouté $30 \mathrm{~cm}^{3}$ de potasse méthanolique à $6 \mathrm{p}$. Ioo et laissé saponifier trois heures à reflux. Après les extractions habituelles, nous avons obtenu:
Fraction insaponifiable $\ldots \ldots \ldots \ldots \ldots \ldots \ldots \ldots \ldots \ldots \ldots$

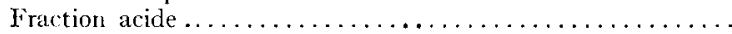
Hydrosoluble perdu $\ldots \ldots \ldots \ldots \ldots \ldots \ldots \ldots \ldots \ldots$
$15,350 \mathrm{gr}$
7,1 :
$2,150)$

- La partie insaponifiable est reprise dans $150 \mathrm{~cm}^{3}$ de méthanol sec, on y ajoute $15 \mathrm{~g}$ de réactif de Girard et $15 \mathrm{~cm}^{3}$ d'acide acétique, on laisse deux heures à refux : il y a formation d'un léger précipité qui disparaît au cours de la réaction. On calcule la quantité de soude $(2 \mathrm{~N})$ nécessaire pour neutraliser les $9 /$ I o de l'acide acétique : pour cela on titre $\mathrm{r} \mathrm{cm}^{3}$ d'acide acétique dans $10 \mathrm{~cm}^{3}$ d'eau par la soude $(2 \mathrm{~N})$ (en présence de bleu de bromothymol) : il faut $8,7 \mathrm{~cm}^{3}$ pour neutraliser $\mathrm{I} \mathrm{cm}^{3}$; pour en neutraliser $13,5 \mathrm{~cm}^{3}$ il en faudra II $_{7}, 5 \mathrm{~cm}^{3}$.

On chasse 10 p. roo du volume de méthanol sous vide à $40^{\circ}$; on refroidit le milieu réactionnel par de la glace et l'on introduit les i $7,5 \mathrm{~cm}^{3}$ de soude $(2 \mathrm{~N})$; on ajoute ensuite de l'eau glacée de telle sorte que le volume final soit de I litre; le pH est 6.

On extrait trois fois par $500 \mathrm{~cm}^{3} \mathrm{~d}$ 'éther, on lave à l'eau, on sèche : fraction éthérée non cétonique : $\mathrm{I} 2,9 \mathrm{~g}$;

fraction hydrosoluble : on l'acidifie par 1 oo $\mathrm{cm}^{3}$ d'acide chlorydrique concentré, en agitant : on obtient une solution approximativement normale. On extrait par 5 fois $500 \mathrm{~cm}^{3} \mathrm{~d}$ 'éther, on lave à l'eau et l'on sèche : fraction cétonique : $\mathrm{r}, 369 \mathrm{~g}$ que l'on chromatographie sur $40 \mathrm{~g}$ d'alumine ; les élutions sont de $100 \mathrm{~cm}^{3}$.
$1-3$ éther de pétrole-benzène $1: 1 \ldots \ldots \ldots \ldots \ldots \ldots \ldots$
$1-6$ éther de jétrole-benzène $\ldots \ldots \ldots \ldots \ldots \ldots \ldots \ldots \ldots$

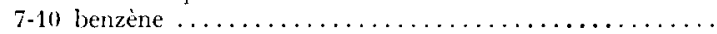
11-12 benzène-éther $9: 1 \ldots \ldots \ldots \ldots \ldots \ldots \ldots \ldots \ldots \ldots \ldots$

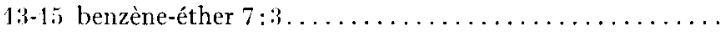
$16-20$ benzène-éther $1: 1 \ldots \ldots \ldots \ldots \ldots \ldots \ldots \ldots \ldots \ldots$

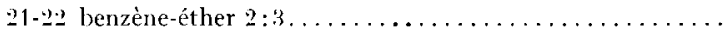

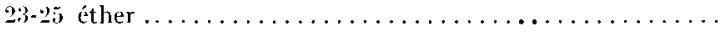

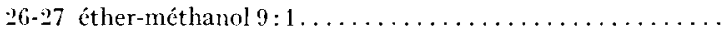

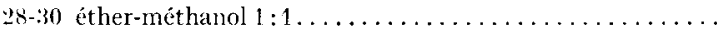

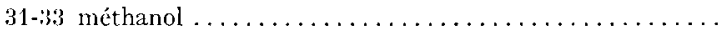
$31-36$ chloroforme-acide acétique $19: 1 \ldots \ldots \ldots \ldots \ldots \ldots$

$11,5 \mathrm{mgr}$
traces
traces
traces
$19, .3 \mathrm{mgr}$
$316,7 \mathrm{mg}$
$61,8 \mathrm{mg}$
$81,2 \mathrm{mg}$
$150,6 \mathrm{mg}$
$128,3 \mathrm{mg}$
$15,3 \mathrm{mg}$
$155,5 \mathrm{mg}$

fractions I $^{-1}$ - $_{5}$ : après cristallisation dans l'acétone, on obtient des cristaux $\mathrm{F} 74^{\circ}$. Liebermann négatif. Pas de spectre dans l'U V. La réaction à l'iodoforme laisse le produit inchangé.

Analyse élémentaire : $\mathrm{C}_{34} \mathrm{H}_{68} \mathrm{O}_{2}$ trouvé en pourcentage : $\mathrm{C} 80,95$ calculé en pourcentage: C 80,24

H I 3,27 P'M déterminé Rast 494;

$\mathrm{H}_{13}, 47$ PM calculé 508 .

fractions i 6-20: après cristallisation dans l'acétone, les cristaux fondent à $82^{\circ}$; le point de fusion de mélange d'une palmitone authentique avec les cristaux de cette fraction ne présente pas de dépres. sion.

fractions $26-27$ : après cristallisation dans l'acétone, on obtient une poudre amorphe $\mathrm{F} 40-45^{\circ}$. La réaction de Liebermann est négative.

fractions 28-30: cette fraction cristallise dans l'acétone à $\circ^{\circ}$, mais se trouve sous forme d'huile à température ordinaire. La réaction de Liebermann est négative. 

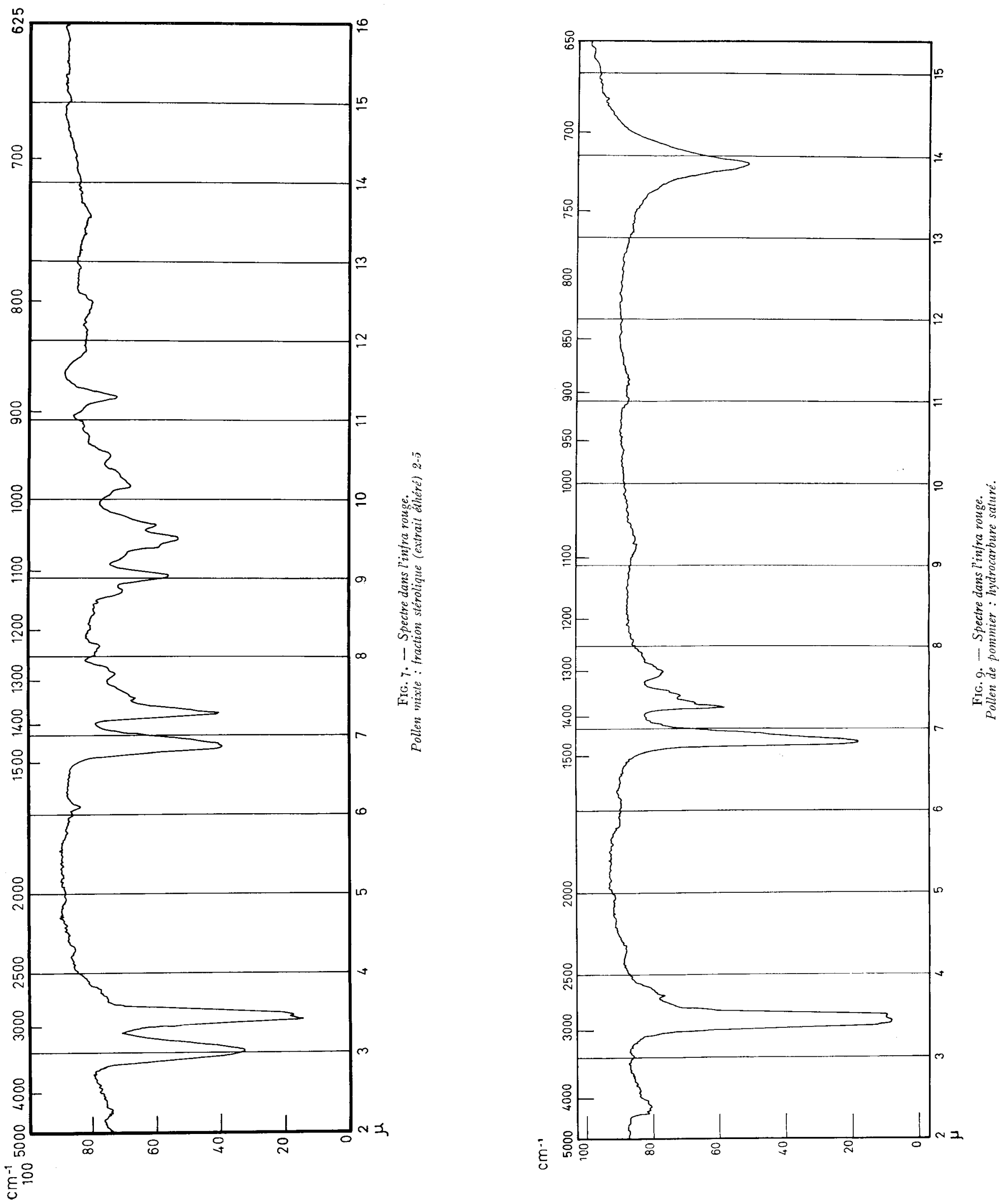



\section{B. -- Extrait alcoolique :}

Il représente $23 \mathrm{p}$. Ioo du poids du pollen. I I g de cet extrait sont chromatographiés sur I Iog de silicate, élutions de $250 \mathrm{~cm}^{3}$ :

\begin{tabular}{|c|c|c|}
\hline $1-2$ & chloroforme-méthanol $95: 5 \ldots$ & $2,081 \mathrm{~g}$ \\
\hline 3 & chloroforme-méthanol $9: 1 \ldots \ldots \ldots \ldots \ldots \ldots$ & $0,162 \mathrm{~g}$ \\
\hline 't & chloroforme-méthanol $85: 15 \ldots \ldots \ldots \ldots \ldots \ldots$ & $0,169 \Leftrightarrow$ \\
\hline 5 & chloroforme-méthanol $3: 1 \ldots \ldots \ldots \ldots \ldots \ldots$ & 0,310 \\
\hline $6-8$ & chloroforme-méthanol $1: 1 \ldots \ldots \ldots \ldots \ldots \ldots \ldots$ & 4,921 \\
\hline $9-12$ & 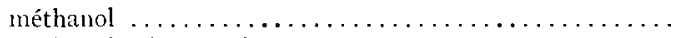 & 1,380 \\
\hline $13-1 t^{\prime}$ & acétique $49: 1 \ldots \ldots \ldots \ldots \ldots \ldots$ & $1,9 \geq 1 \mathrm{~g}$ \\
\hline
\end{tabular}

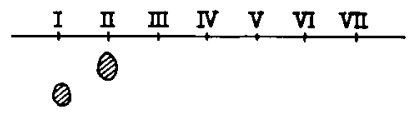

0
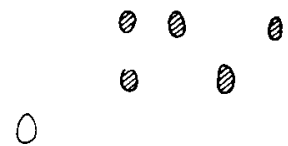

FIG. 8. - Chromalographie descendanle sur papier

Pollen mixte : extrait alcoolique ;

fractions $I \cdot 2$ : partie insoluble dans l'éther après hydrolyse acide :

I : xylotriose;

II : produit étudié après une hydrolyse de I heure ;

III : xylobiose ;

IV : produit étudié après une hydrolyse de 2 heures ;

$V$ : arabinose ;

VI : xylose ;

VII : mannose ;

solvant de développement : butanol-acide acétique -eiı ;

révélation : phtalate acide d'aniline;

papier Whatman $\mathbf{n}^{0} \mathbf{I}$.

Tests fonctionnels

\begin{tabular}{|c|c|c|c|c|}
\hline & IIydroxamique & LIEBERMANN & DNP & LEGAL \\
\hline $1-2$ & + pour esters & + vert & $\cdots$ & - \\
\hline$: ;$ & + pour esters & -- & 一 & - \\
\hline i & + pour esters & $\cdots$ & $一$ & $\rightarrow$ \\
\hline 5 & + pour esters & -- & $-\cdots$ & - \\
\hline$t i-k$ & + pour esters & + rouge & $\cdots$ &. \\
\hline $9-12$ & + jour phénols & + rouge & + & - \\
\hline $13-14$ & + pour phénols & + rouge & - & - \\
\hline
\end{tabular}

Etude des fractions 1-2 :

Ces fractions sont séparées par l'éther, on obtient :

a) un éthérosoluble : $0,680 \mathrm{~g}$. La réaction de Liebermann est positive. De cet éthérosoluble a été isolé le 24 -méthylène-cholestérol (voir le chapitre consacré à l'isolement de ce produit).

b) une poudre jaune insoluble: $1,4 \mathrm{~g} \mathrm{~F}>35^{\circ}$ (avec décomposition). Sa combustion est incomplète même après essai de solubilisation des sels éventuels.

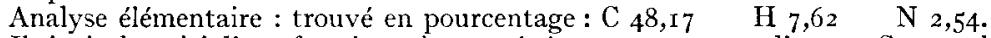

Il s'agit donc ici d'une fraction très oxygénée, contenant peu d'azote. Cette substance n'est pas saponifiable. Elle n'est soluble que dans la diméthylformamide et le $n$-butanol. La réaction de Lie- 
bermann donne une coloration rouge caractéristique de terpènes. La réaction d'TirLICII (I899) est positive.

Nous avons soumis la substance à une série d'hydrolyses :

1. - hydrolyse dans l'acide chlorydrique (12 N) :

Cette hydrolyse nous foumit un hydrosoluble ( 5 p. 10o) sur lequel nous avons fait

- des chromatographies circulaires dans le système II:

la révélation à l'acide périodique est positive ;

au phtalate acide d'aniline positive ;

à la ninhydrine faiblement positive.

- des chromatographies descendantes dans les systèmes II, III, IV : recherche des acides aminés : il n'y a pas de produits révélables à la ninhydrine.

recherches des sucres : les différentes méthodes de révélation employées (acide périodique, phloroglucine (Discire, i 957), phtalate acide d'aniline) font apparaître des taches qui migrent très peu : ce sont vraisemblablement des sucres condensés sous une trop forte hydrolyse.

Pour vérifier cette hypothèse, nous avons soumis l'hydrosoluble à :

\section{2. - hydrolyse dans l'acide chlorydrique $(2 \mathrm{~N})$ :}

Durant une heure pour une partie de l'hydrosoluble, durant deux heures pour l'autre partie : chromatographies effectuées dans les systèmes I et III, révélation par le phtalate acide d'aniline et le phloroglucinol. On remarque (fig. 8) :

- après une heure d'hydrolyse : aucun changement ;

- après deux heures : I tache à la hauteur du xylobiose ;

I tache à la hauteur du xylose;

I tache à la hauteur du mannose et arabinose;

en révélant par l'acide périodirque une tache ia la hauteur du glycérol daus les 2 cas.

TABLEAU 2

Activite biologique comparie de différentes fractions du pollen mixte.

\begin{tabular}{|c|c|c|c|c|}
\hline & \multicolumn{4}{|c|}{ Dilutions } \\
\hline & $1 / 10$ & $1 / 100$ & $1 / 1000$ & $1 / 10000$ \\
\hline $\begin{array}{l}\text { Substance de référence : } \\
\text { Pollen brut pur } \ldots \ldots \ldots \ldots \ldots \ldots \ldots \ldots \ldots \ldots \\
\text { Saccharose } \ldots \ldots \ldots \ldots \ldots \ldots \ldots\end{array}$ & $\begin{array}{l}+5 \\
+1\end{array}$ & $\begin{array}{r}+1 \\
11\end{array}$ & $-+\mathbf{t}$ & $\div$ \\
\hline $\begin{array}{l}\text { Extrait éthéré brut ............. } \\
\text { Partie insaponifiable de l'extrait } \\
\text { éthéré ..................... } \\
\text { Partie acicle de l'extrait éthéré .. }\end{array}$ & $\begin{array}{r}+5 \\
+\quad 1 \\
11\end{array}$ & $\begin{array}{l}-i \\
-i \\
-i\end{array}$ & $\begin{array}{l}-+2 \\
+\end{array}$ & $\begin{array}{l}+ \\
+\end{array}$ \\
\hline 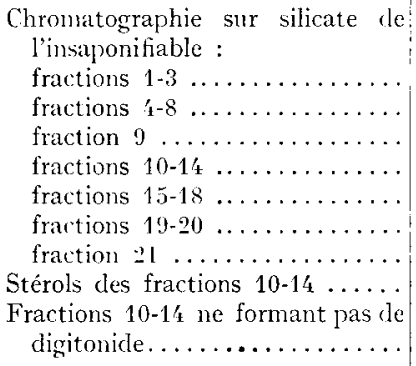 & 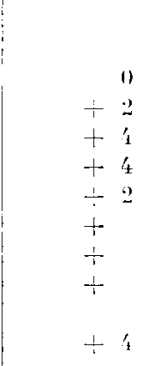 & $\begin{array}{r}+ \\
+\quad 1 \\
+5 \\
+\quad 3 \\
\\
0 \\
0\end{array}$ & $\begin{array}{r}0 \\
+\quad 3 \\
+\quad 2 \\
+\quad\end{array}$ & $\begin{array}{l}+ \\
+ \\
0\end{array}$ \\
\hline Extrait alcoolique $\ldots \ldots \ldots \ldots \ldots$ & $\div 2$ & & & \\
\hline
\end{tabular}




\section{ETUDE DU POLLEN DE POMMIER (Pirus malus)}

Ayant à notre disposition un pollen de pommier pur à 85 p. Ioo, nous avons cherché à identifier, dans ce pollen, les fractions précédemment isolées du pollen mixte.

Nous avons procédé à une extraction à l'éther suivie d'une extraction à l'alcool.

\section{RÉSULTATS \\ A. - Extraction à l'éther :}

Cet extrait est peu abondant. Nous l'avons saponifié en totalité ; la fraction insaponifiable a été séparée en deux parties :

a) Sur la première partie, nous avons cherché les fractions attirant les abeilles: en faisant une chromatographie sur silicate, nous les avons éluées avec un mélange benzène-éther, de la même manière que le pollen mixte. Nous n'avons pu, pour l'instant, pousser plus avant l'étude de ces fractions ;

b) sur la seconde partie, nous avons fait une chromatographie sur alumine; nous avons obtenu :

a) une fraction éluée au benzène, qui est un mélange d'hydrocarbures saturés: en effet, il n'y a pas de fixation d'hydrogène au cours d'une micro-hydrogénation ; après distillation, nous avons recueilli quatre fractions répondant aux formules brutes: $\mathrm{C}_{24} \mathrm{H}_{50}, \mathrm{C}_{25} \mathrm{H}_{52}, \mathrm{C}_{30} \mathrm{H}_{62}, \mathrm{C}_{31} \mathrm{H}_{64}$; ces différentes fractions sont elles-mêmes des mélanges, mais il nous a été impossible, sauf pour la première fraction, de les séparer au moyen de la chromatographie en phase gazeuse, car leurs points d'ébullition sont trop élevés.

ß) une fraction éluée par un mélange éther-méthanol $95: 5$, qui après cle nombreuses cristallisations donne des belles aiguilles blanches $\mathrm{F} 69^{-} 7^{\circ}$. Le spectre IR de cette substance est caractéristique d'un alcool; il s'agit, en fait d'un diol de formule brute $\mathrm{C}_{18} \mathrm{H}_{34} \mathrm{O}_{2}$. Nous avons voulu déterminer s'il s'agissait d'un $\alpha$-glycol, et, dans ce cas voir s'il était possible d'identifier, ou simplement d'isoler, des produits de dégradation: pour cela, nous avons fait une oxydation périodique accompagnée d'une titration : il y a consommation de go p. Ioo de la quantité d'oxygène théoriquement nécessaire pour la rupture de -CHOH-CHOH-; ayant ainsi accuis qu'il s'agissait d'un $\alpha$ glycol, nous avons fait une oxydation chromique sur les produits de l'oxydation périodique, oxydation qui devait transformer les aldéhydes précédemment formés en acides ; puis, sans isoler les produits de réaction, nous avons méthylé les acides éventuels en vue d'en faire une séparation par chromatographie en phase gazeuse : cette chromatographie n'a donné aucun résultat : si l'acide isolé est très ramifié, son manque de volatilité peut le rendre difficilement entraînable.

\section{B. - Extraction à l'alcool}

Cet extrait est très abondant et fortement coloré. Comme pour le pollen mixte, nous avons fait une chromatographie de l'extrait sur silicate. La fraction, éluée par un mélange chloroforme-méthanol $95: 5$, est séparée par l'éther en :

- une fraction éthérosoluble qui contient du 24-méthylène-cholestérol ;

- une fraction insoluble qui est une poudre jaune clair F I IO-I70 $0^{\circ}$, qui contient 
6 p. Ioo d'azote. Nous avons essayé de purifier cette substance par un partage entre le butanol et l'eau : la fraction hydrosoluble est peu abondante; la fraction soluble dans le butanol est soumise :

- à une saponification. Nous avons:

- très peu de fraction insaponifiable;

- une fraction acide qui présente 2 maxima dans l'UV : 1'un à $225 \mathrm{~m} \mu$, l'autre à $285 \mathrm{~m} \mu$. La masse moléculaire moyenne de ce produit est 226 (déterminé par titration) ;

- une fraction intermédiaire, insoluble dans l'éther et l'eau, qui a une masse moléculaire de I380 (déterminée par titration).

Le produit brut, avant séparation butanol-eau, avait comme masse moléculaire déterminée par titration I400. On peut donc considérer les deux produits comme identiques.

La faible proportion d'hydrosoluble et son manque de réactivité à la ninhydrine montre qu'il y a peu d'acides aminés et que ceux-ci peuvent provenir d'impuretés, telles que les débris cellulaires. Nous cherchons à mettre au point des solvants permettant une meilleure séparation de cette fraction.

- A différentes hydrolyses : ceci en vue de rechercher les sucres (un dosage à 1'anthrone fortement positif nous avait convaincu deleur présence) et les acides aminés par chromatographie sur papier.

- Recherche des sucres : Nous avons pu mettre en évidence, au moyen de différentes révélations, des produits situés sur le chromatogramme à la hauteur du glycérol, de l'arabinose, du xylose et du glucose.

- Recherche des acides aminés : après de nombreuses chromatographies et grâce à la technique de l'électrophorèse, nous avons pu montrer qu'il existe de l'ornithine : un dosage selon VAN Styke, modifié par ChINARD (I952), montre qu'il y a 0,2 p. Ioo d'ornithine dans l'hydrolysat. Les autres acides aminés restent groupés sous forme de peptides et toutes les tentatives de les séparer ont échoué jusqu'à présent.

\section{CONClusions}

Nous avons retrouvé, dans le pollen de Pirus malus, le 24-méthylène-cholestérol isolé d'un pollen mixte.

Il semble exister, à côté des acides aminés ordinaires, de l'ornithine.

\section{DESCRIPTION DES EXPERIENCES}

\section{A. - Extraction à l'éther}

Cet extrait est peu abondant, il correspond à I,7 p. 100 du poids du pollen. Nous l'avons saponifié en totalité : on ajoute à $17,7 \mathrm{~g}$ (dissous dans $30 \mathrm{~cm}^{3}$ de benzène), $60 \mathrm{~cm}^{3}$ de potasse méthanolique $(2 \mathrm{~N})$ et on laisse 18 heures à reflux. Après épuisement à l'éther, cette phase éthérée est lavée à l'eau ; amenée à sec, elle donne $8,5 \mathrm{~g}$ de partie insaponifiable ; la phase acqueuse est acidifiée par l'acide chlorydrique $(2 \mathrm{~N})$ et extraite à l'éther, cet éther est lavé à l'eau et fournit, après évaporation, $8,9 \mathrm{~g}$ de partie acide.

La fraction insaponifiable est divisée en deux parties :

1) Première partie : 4,8 g sont chromatographiés sur $90 \mathrm{~g}$ d'alumine ; les élutions sont de $200 \mathrm{~cm}^{3}$.

\begin{tabular}{|c|c|c|}
\hline $1-3$ & benzène ............. & $2,840 \mathrm{~g}$ \\
\hline $4-7$ & benzène-éther $95: 5 \ldots$ & $1,0+8$ \\
\hline $8-9$ & 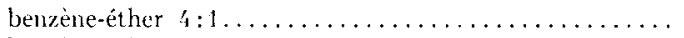 & $0,28 \div 0$ \\
\hline 10 & 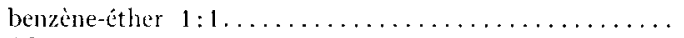 & 0,083 \\
\hline 1 & 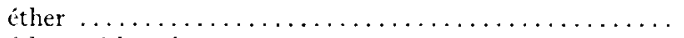 & $0,066^{\prime} \mathrm{t}$ \\
\hline $12-13$ & éther-méthanol $95: 3 \ldots \ldots \ldots \ldots \ldots \ldots \ldots \ldots \ldots \ldots \ldots$ & $0, \mathfrak{\prime}^{\prime} \mathrm{J}^{\prime} \mathrm{t}$ \\
\hline $11^{\prime}$ & méthanol $\ldots \ldots \ldots \ldots \ldots \ldots \ldots \ldots \ldots \ldots$ & $0,066^{\prime}$ \\
\hline
\end{tabular}


a) Etude des fractions $\mathrm{I}-3$ : Nous avons distillé ces fractions dans un tube à boules sous $0,05 \mathrm{~mm}$; nous avons obtenu :

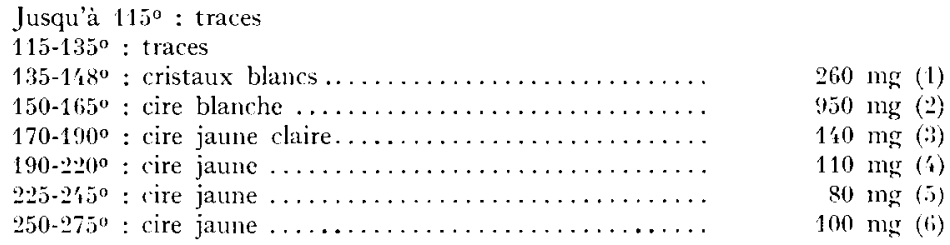

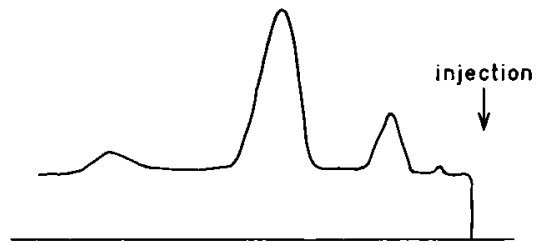

III. Io. - Chromatographie en phase gazeuse d'un mélange d'hydrocarbures

Phase stationnaire : silicone ;

température : $240^{\circ}$;

pression à l'entrée : $235 \mathrm{~mm}$;

pression à la sortie : $15 \mathrm{~mm}$;

débit d'azote $: \mathrm{I}, 6 \mathrm{l} / \mathrm{h}$;

sensibilité : Ioo $\mathrm{mA}$;

appareil Griffin et George.

Chaque fraction de distillation a été recristallisée plusieurs fois dans le méthanol ; on obtient des plaquettes incolores. Les analyses élémentaires de ces produits ont montré c pu'il s'agissait de carbures saturés (pas de fixation d'hydrogène au cours d'une micro-hydrogénation); la masse moléculaire, donnée par Rast, nous a permis de calculer la formule brute ; les spectres IR (fig. 9) ont confirmé la nature aliphatique de ces hydrocarbures; le test au tétranitrométhane est négatif. De plus, les spectres pris dans l'UV ne présentent aucune bande caractéristique.

(I) $\mathrm{F} 4 \mathrm{OO}_{4} \mathrm{I}^{\mathrm{I}}$, analyse : $\mathrm{C}_{23} \mathrm{H}_{48}$

trouvé en pourcentage : $\mathrm{C} 85,08$

calculé en pourcentage : C $85, \mathrm{I} 2$

$\mathrm{H}_{14}, 62$ P. M. (Rast) 323 ;

H ${ }_{14}, 88$ P.M. 324 .

Cette fraction a pu être résolue, par chromatographie en phase gazeuse, en quatre substances (fig. Io) : aucune autre fraction de distillation n'a pu être séparée de la sorte; les points d'ébullition sont trop élevés :

(2) $\mathrm{F} 44-47^{\circ}$, analyse $\mathrm{C}_{24} \mathrm{H}_{50}$ trouvé en pourcentage : C $85,6 \mathrm{I}$ calculé en pourcentage : C $85, \mathrm{I} 2$

II I 4,44 P', M. déterminé (Rast) 337 ;

(3) $\mathrm{F} 55^{\circ}$, analyse $\mathrm{C}_{25} \mathrm{H}_{52}$ :

trouvé en pourcentage : $\mathrm{C} 85,63$

calculé en pourcentage : C 85,12

II I4,37 P. M. déterminé (Rast) 357 ;

H ${ }_{14}, 88$ P. M. calculé $35^{2}, 67$.

(4) $\mathrm{F}_{5} 8^{\circ}$, analyse $\mathrm{C}_{30} \mathrm{H}_{62}$ :

trouvé en pourcentage : $\mathrm{C} 85, \mathrm{I} 3$

calculé en pourcentage : $\mathrm{C} 85, \mathrm{I} 2$

H I4,6r P. M. déterminé (Rast) 425 ;

H I 4,88 P. M. calculé 422,80.

(5) F $55^{-60^{\circ}}$, analyse $\mathrm{C}_{31} \mathrm{H}_{64}$ :

trouvé en pourcentage : $\mathrm{C} 85,57$

II ${ }_{14,21}$ P. M. déterminé (Rast) 432 ;

calculé en pourcentage : C 85, I 2

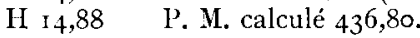

(6) $\mathrm{F} 60^{\circ}$

b) Etude des fractions I $2-\mathrm{I} 3_{3}$ : Ces fractions sont très colorées; on les cristallise une première fois dans l'acétone ; les cristaux obtenus sont dissous dans l'éther de pétrole chaud, le produit qui préci- 
pite, quand on laisse refroidir la solution, est cristallisé dans un mélange benzènc-éther $2:$ i ; les aiguilles blanches (30 $\mathrm{mg})$ qui se séparent fondent à $69-70,5^{\circ}$.

- bande hydroxyle libre à $3300 \mathrm{~cm}^{-1}$;

- bande hydroxyle primaire à I 350 et $1050 \mathrm{~cm}^{-1}$;

- bandes hydroxyles secondaires à I I 20 et $930 \mathrm{~cm}^{-1}$ (fig. I I).

Le test de CARr et PRICE (Ig26) est positif (coloration rouge) tandis que celui au tétranitrométhane est négatif, LIANG (1941).

Analyse élémentaire : $\mathrm{C}_{16} \mathrm{Ir}_{34} \mathrm{O}_{2}$ trouvé en pourcentage : $\mathrm{C}_{74,27}$ calculé en pourcentage : $\mathrm{C} 7+, 36$

II I $2,94 \quad$ P. M. déterminé (Rast) 285 ;

II 12,38 I'. M. déterminé $25^{8,4}$.

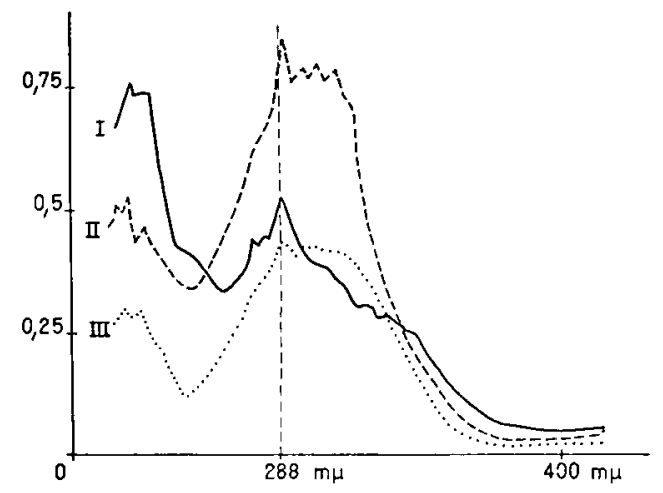

FIC. I2. - Spectres dans l'ullra violet et le i'isible.

Pollen de pommicr : extrait alcoolique;

fractions I-2 : partic insoluble dans l'éther ;

1 : fractions brute ;

II : fraction après hydrolyse acide : ćthćrosoluble ;

III : fraction après saponification : fraction soluble dans le butanol ;

spectres faits dans l'alcool : concentration ramenéc à o, $\mathrm{r} 1 \mathrm{mg} / \mathrm{cm}^{3}$.

\section{I. - Oxydation périodique :}

Cette oxydation saccompagne d'une titration permettant de calculer la quantité d'oxygène consommé : jo mg de diol dissous dans $4 \mathrm{~cm}^{3}$ d'alcool, ont été oxydés durant une nuit par $2 \mathrm{~cm}^{3}$ d'acide périodique 0, i I $\mathrm{N}$, en présence de $4 \mathrm{~cm}^{3}$ d'anhydride arsénieux $0,09 \mathrm{~N}$ et de $0,5 \mathrm{~cm}^{3}$ d'iodure de potassium à $20 \mathrm{p}$. I 00 . Le titrage se fait parl'iode o, 1 o I N (en présence d'amidon) et par comparaison avec un témoin ne contenant que les réactifs. Un simple calcul d'équivalence nous a permis de voir que l'oxygénation avait eu lieu (il y a utilisation de 90 p. 100 de la quantité d'oxygène qui est théoriquement nécessaire). Nous sommes donc en présence d'un $\alpha$-glycol.

\section{2. - Oxydation périodique:}

Après épuisement à l'éther du mélange réactionnel, nous avons obtenu $9 \mathrm{mg}$ d'un aldéhyde (ou d'un mélange d'aldéhydes) qui ont été dissous dans $1 \mathrm{~cm}^{3}$ d'acide acétique glacial (MERCK). A cette solution on ajoute goutte à goutte, durant 3 heures, $3 \mathrm{~cm}^{3}$ dacide chromique ì I p. roo dans l'acide acétique glacial : le milieu réactionnel doit conserver une teinte brun rouge. On laisse une nuit en contact. On ajoute alors $0,5 \mathrm{~cm}^{3}$ d'alcool et l'on extrait à l'éther ; la phase éthérée est lavée puis séchéc et amenée à sec : nous obtenons to $\mathrm{mg}$ d'une fraction acide.

\section{3. - Methylation et chromatographie :}

Cette substance est méthylée par le diazométhane dans l'éther ; la chromatographie gazeuse (à $240^{\circ}$ sous $319 \mathrm{~mm}$ ) ne donne aucun résultat.

L'appareil a été étalonné par les esters méthyliques des acides $\mathrm{C}_{14} \mathrm{H}_{28} \mathrm{O}_{2}, \mathrm{C}_{15} \mathrm{II}_{30} \mathrm{O}_{2}$ et $\mathrm{C}_{18} \mathrm{H}_{32} \mathrm{O}_{2}$; nous avions, en effet, pensé que l'aldéhyde formé pourrait être celui de l'acide en $C_{15}$ non ramifié. 

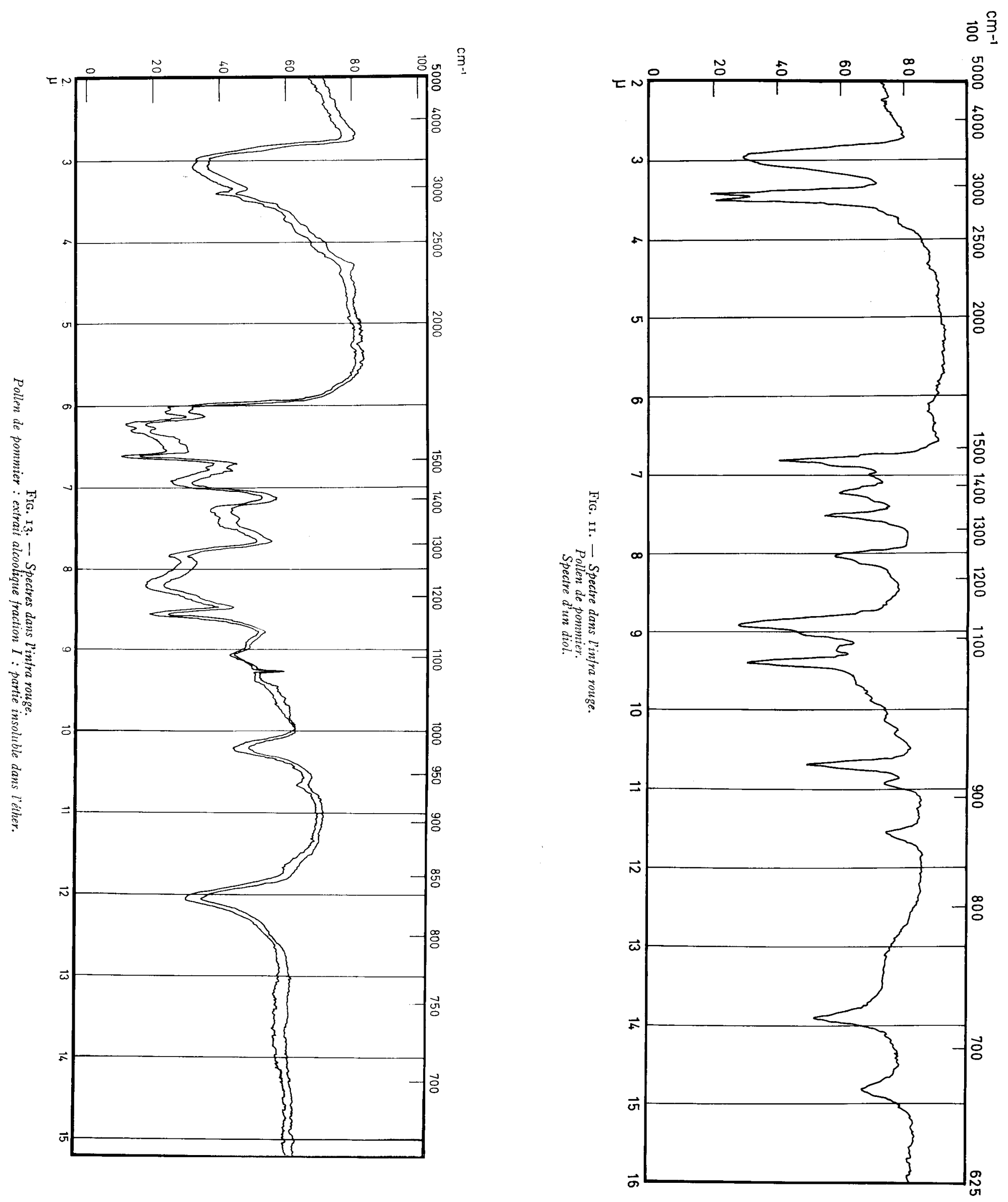

I I). Deuxième partie : I,5 d'insaponifiable sont chromatographiés sur I $5 \mathrm{~g}$ de silicate ; élutions de $50 \mathrm{~cm}^{3}$ :

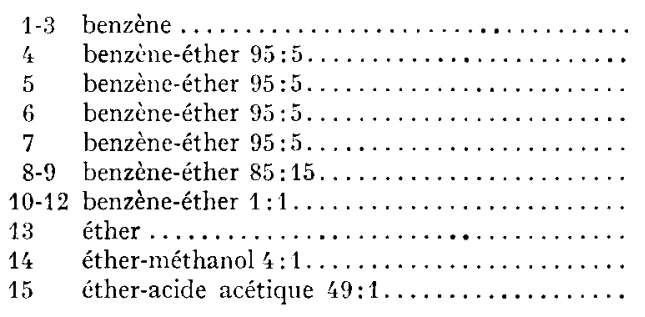

Test de butinage

$1,333 \mathrm{~g}+++$
$0,200 \mathrm{~g}++++$
$0,813 \mathrm{~g}++++$
$0,220 \mathrm{~g}++$
$0,020 \mathrm{~g}+$
$0,127 \mathrm{~g}+$
$0,100 \mathrm{~g}$
$0,025 \mathrm{~g}$
$0,020 \mathrm{~g}$
$0,131 \mathrm{~g}$

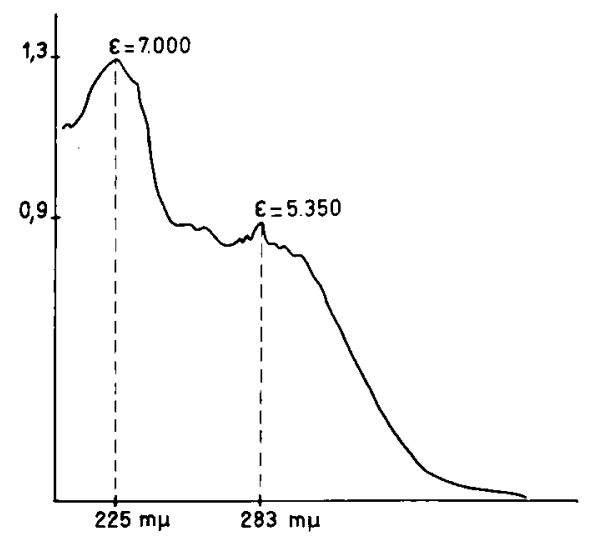

FIG. I4. - Spectre dans l'ultra violet.

Pollen de pommier : extrait alcoolique fractions $I-2$ : partie insoluble dans l'éther, partie acide de la saponification; spectre fait dans l'alcool $(0,05 \mathrm{mg} / \mathrm{cc})$.

L.es élutions benzène-éther $95: 5$ fournissent des substances qui, soumises aux tests biologiques, donnent des réactions positives, d'intensité semblable à celles des fractions éluées par les solvants correspondants dans la chromatographie d'un pollen mixte.

\section{B. - Extraction à l'alcool}

Cet extrait correspond à $24 \mathrm{p}$. Ioo du poids du pollen. Nous chromatographions to g de cet extrait (dissous dans $50 \mathrm{~cm}^{3}$ d'un mélange chloroforme-méthanol $95: 5$ ) sur $50 \mathrm{~g}$ de silicate ; les élutions sont de $100 \mathrm{~cm}^{3}$ :

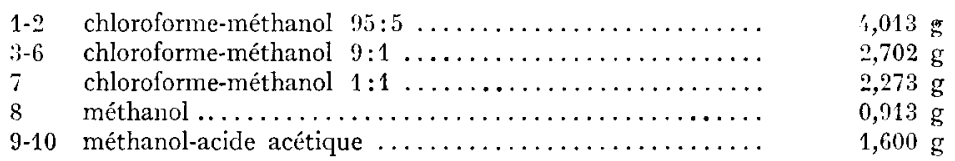

Etude des fractions $\mathbf{I}-2$ : (spectre UV fig. I2, spectre IR fig. I3).

a) fraction éthérosoluble : c'est de cette fraction que nous avons isolé le 24 -méthylène-cholestérol (voir chapitre suivant).

b) fraction insoluble dans l'éther : c'est une poudre jaune clair F I I0-I $70^{\circ}$.

Analyse élémentaire : trouvé en pourcentage C 66,45 II 7,49 N 6,78. 
Le dosage à l'anthrone est positif : il y a 2,5 p. Ioo de sucres totaux (calculés en glucose). Un dosage de pentoses selon TrACEY (I950) montre qu'il y en a I,4 p. Ioo ; il y aurait donc I,2 p. IDO d'hexoses dans cette fraction.

Nous avons essayé de purifier cette substance, vraisemblablement fort complexe, de la façon suivante :

- essai de partage entre le butanol et l'eau : on dissout $100 \mathrm{mg}$ du produit dans $20 \mathrm{~cm}^{3}$ de butanol ; ce butanol est lavé trois fois par $10 \mathrm{~cm}^{3}$ d'eau ; chacune de ces phases aqueuses est épuisée à son tour, par deux fois $10 \mathrm{~cm}^{3}$ de butanol. Après évaporation sous vide de chaque solution, nous avons :

I. - une fraction hydrosoluble : soit $4 \mathrm{mg}$ (soit $4 \mathrm{p}$. Ioo du produit de départ) sur lesquels nous avons fait une chromatographie radiale dans le système II : la révélation au phtalate acide d'aniline est négative, celle à la ninhydrine est très légèrement positive.

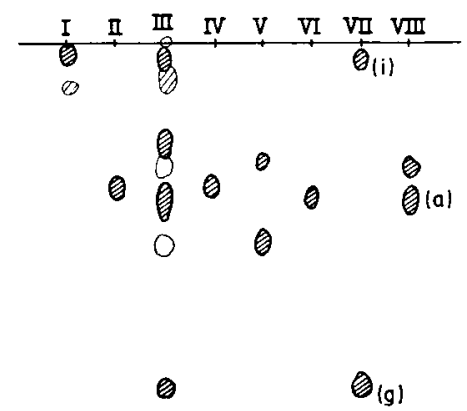

FIG. 15. - Chromatographie descendante sur papier.

Pollen de pommier : extrait alcoolique ;

fractions I-2 : partie insoluble dans l'éther après hydrolyse acide;

solvant de développement : butanol-acide formique-eau ;

révélation : acide périodique/benzidine ;

I : xylotriose, xylobiose ;

II : fructose ;

III : hydrolysat ;

IV : mannose ;

$\mathrm{V}$ : ribose, glucose ;

VI : xylose ;

VII : inositol (i), glycérol (g);

VII : galactose, arabinose (a) ;

papier Whatman $n^{\circ} \mathrm{I}$.

2. - une fraction soluble dans le butanol : $96 \mathrm{mg}$ (soit 96 p. Ioo du produit). Une chromatographie radiale dans le système II nous indique, après des révélations par le phtalate acide d'aniline et la ninhydrine qui sont négatives, que ni les sucres, ni les acides animés n'existent sous forme libre.

Une saponification de $90 \mathrm{mg}$ (dissous dans $2 \mathrm{~cm}^{3}$ de butanol) par $220 \mathrm{mg}$ de potasse (potasse butanolique $2 \mathrm{~N}$ ) durant 3 heures donne, après les extractions habituelles (éther-eau)

- un insaponifiable : soit 8 p. 100 du produit mis à saponifier.

- une partie acide : qui correspond à 30 p. Ioo de ce même produit. La masse moléculaire (déterminée par titration) est de 266 ; cette fraction présente 2 maxima dans l'UV: un à 225 mu et l'autre à $283 \mathrm{mu}$ (fig. I4).

- une partie intermédiaire : insoluble dans l'éther et dans l'eau, soluble dans le butanol, qui représente $62 \mathrm{p}$. Ioo de la substance initiale. Sa masse moléculaire, obtenue par titration, est de I 380 (fig. I 2 spect re UV).

Le produit brut avait comme masse moléculaire i 400 (déterminée par titration). Pour essayer d'isoler les acides aminés et les sucres qui semblent présents dans cet éthéro-insoluble, nous avons fait des hydrolyses dans différentes conditions :

- hydrolyse avec l'acide chlorydrique $(2 \mathrm{~N})$ : durée 2 heures à $105^{\circ}$.

Cette hydrolyse nous fournit 3 p. Ioo d'hydrosoluble après une extraction à l'éther. C'est une hydrolyse très douce qui nous a permis de rechercher la présence de sucres et celles des acides aminés.

Sur la fraction éthérosoluble, nous avons uniquement fait un spectre UV (fig. I 2 ).

Recherche des acides aminés : Nous avons fait des chromatographies descendantes dans les systèmes II et IV : il n'apparaît qu'une seule tache, après traitement à la ninhydrine : celle-ci se trouve à la hauteur de l'acide $\alpha$, $\varepsilon$-diaminopimélique. 

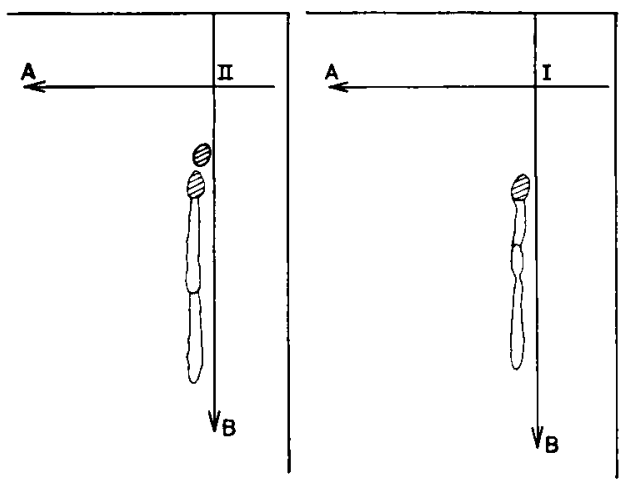

FIG. I6. - Chromatographies descendantes sur papier (bi-dimensionnelles)

Pollen de pommier : extrait alcoolique;

fractions $\mathrm{I}^{-2}$ : partie insoluble dans l'éther, hydrolyse acide;

solvants de développement : sens de $\mathrm{A}$ : butanol-acide acétique-eau ;

papier Whatman $n^{0} \mathbf{r}$;

sens de B : phénol-eau (CNK);

chromatographie I : hydrolysat seul ;

chromatographie II : hydrolysat + acide $\alpha, \varepsilon$-diaminopimélique.

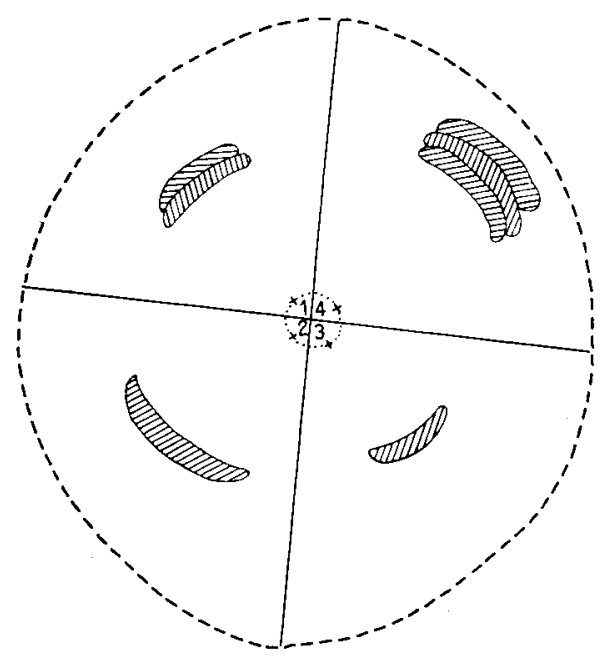

FIG. I7. - Chromatographie circulaire sur papier.

Pollen de pommier : extrait alcoolique ;

fractions $\mathrm{I}-2:$ partie insoluble dans l'éther, hydrolyse acide;

solvant de développement : système de $\mathrm{E}$. WORK ;

révélation : ninhydrine ;

papier Whatman $n^{\circ} \mathrm{I}$;

I: acide diaminopimélique (taches jaunes : $R_{f}: 0,57$ et 0,64 );

II : cystéine (tache rose $\left.: R_{f}: 0,58\right)$;

III : acide cystique (tache grise $\left.: R_{f}: 0,55\right)$.

IV : produit étudié (taches violette, bleue, pourpre : $\mathrm{R}_{f}: 0,66-0,77$ et 0,9 ). 
Recherche des sucres : Les chromatographies ont été réalisées dans les systèmes II, III et IV : Ia révélation par l'acide périodique montre la présence de glycérol.

Il y a apparition de quatre taches lorsque l'on fait agir soit le phtalate acide d'aniline, soit le phloroglucinol :

I tache à la hauteur de l'arabinose ;

I tache à la hauteur du xylose ;

I tache à la hauteur du glucose ;

I tache juste en dessous de la ligne de départ (peut-être du xylotriose) (fig. I 5 ). L'arabinose et le xylose ont même $\mathbf{R}_{\boldsymbol{f}}$ dans le butanol, mais sont bien séparés dans les autres systemes.

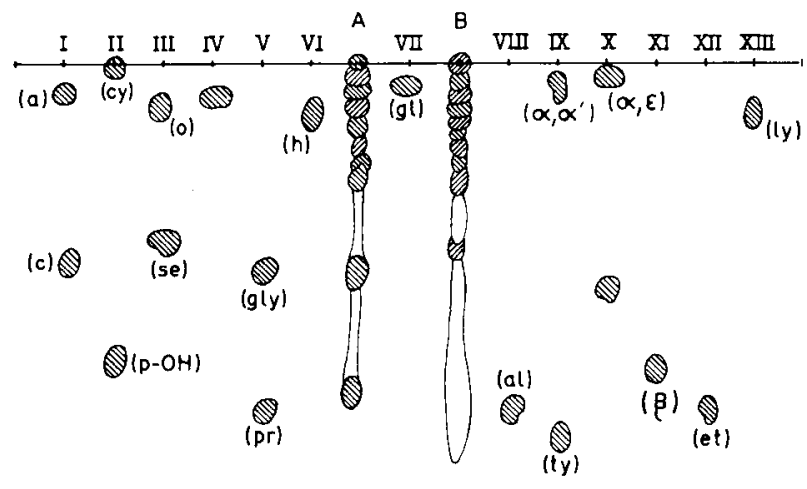

(me)

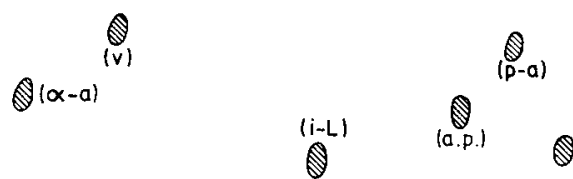

Fig. I8. - Chromatographie descendante sur papier.

Pollen de pommier : extrait alcool-ćther; fractions $1-2$ : insoluble dans l'éther;

I : acide aspartique (i), citrulline (c) ;

II : cystéine (cy), hydroxy-proline (pOH) ;

III : ornithine (o), sérine (se) ;

IV : acide $\alpha, \gamma$-diaminobutyrique, acide $\alpha$-aminobutyrique $(\alpha$ a) ;

$V$ : proline (pr), glycocolle (gly);

VI : histidine $(h)$, valine (v);

VII : glucosamine : IICl (gl), méthionine (mé) ;

VIII : alanine (al), iso-leucine (i-l);

IX : acide $\alpha, \alpha^{\prime}$-diaminobutyrique $\left(\alpha, \alpha^{\prime}\right)$, tyrosine (ty) ;

$\mathrm{X}$ : acide $\alpha, \varepsilon$-dianinopimélique $(\alpha, \varepsilon)$, acide glutamique ;

$\mathrm{XI}: \beta$-alanine ( $\beta$ ), acide pipécolique (a. $p$ );

XII : phényl-alanine ( $\mathrm{p}-\mathrm{a})$, éthanolamine (et) ;

XIII : lysine, HCl (ly), leucine (l) ;

A : produit brut, après hydrolyse ;

$\mathrm{B}$ : produit purifié (fraction soluble dans le butanol), après hydrolyse ;

solvant de développement : butanol-acide formique-eau ;

papier Arches 304, lavé à l'eau ;

révélation : ninhydrine.

- hydrolyse avec l'acide chlorydrique $(6 \mathrm{~N})$ : durée 30 heures à $105^{\circ}$.

Cette hydrolyse, assez brutale, nous donne à peu près 7 p. 10o d'hydrosoluble sur lequel nous avons uniquement essayé d'identifier les acides aminés : avec un traitement aussi violent, les sucres risquent d'être abîmés ou tout au moins de subir le phénomène de réversion.

Nous avons utilisé quatre types de chromatographies : 


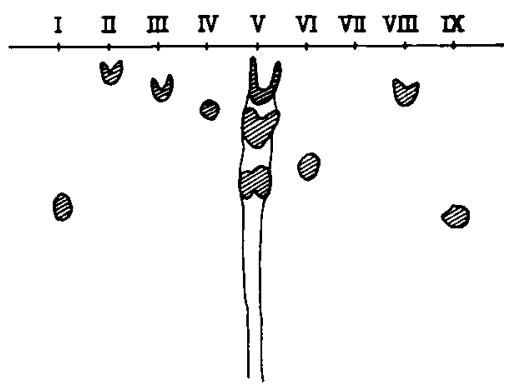

FIG. 19. - Chromatographie descendante sur papier.

Pollen de pommier : extrait alcoolique ;

fractions I-2 : partie insoluble dans l'éther;

I : lysine ;

II : acide $\alpha, \alpha$,-diaminoadipique ;

III : acide $\alpha, \gamma$, diaminobutyrique ;

IV : acide aspartique ;

$\mathrm{V}$ : produit étudié après hydrolyse ;

VI : sérine ;

VII : valine;

VIII : ornithine ;

IX : acide glutamique ;

solvant de développement : phénol tamponné $\mathrm{pH} 4$;

papier Arches 304 lavé au tampon $\mathrm{pH} 4$;

révélation : ninhydrine.

anode

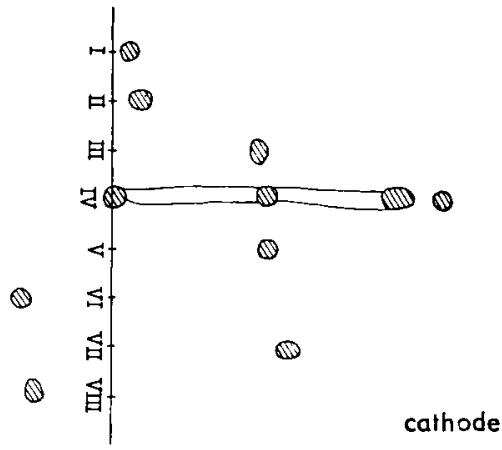

FIG. 20. - Electrophorèse sur papier.

Pollen de pommier : extrait alcoolique ;

fractions I-2 : partie insoluble dans l'éther ;

tampon véronal-sodique $\mathrm{pH} \mathrm{8,2}$ (300v, $20 \mathrm{~mA})$;

appareil LKB ;

parpier Arches 304 imprégné de tampon ;

I : sérine ;

II : valine;

III : arginine ;

IV : fraction étudiée après hydrolyse acide ;

$\mathrm{V}$ : ornithine ;

VI : acide aspartique ;

VII : lysine ;

VIII : acide glutamique ;

révélation : ninhydrine.

Annales de l'Abeille. - $\mathbf{1 9 6 2 .}$ 
x) Chromatographies bi-dimensionnelles : étant donné que nous avions localisé une tache ì la hauteur de l'acide $\alpha, \varepsilon$-diaminopimélicue (DAP), nous avons voulu vérifier la présence de cet acide dans notre hydrolysat ; pour cela nous avons fait deux chromatographies bi-dimensionnelles (premier système I ; deuxième système IV), l'un sur l'hydrolysat seul, l'autre sur l'hydrolysat + DAP (fig. I6).

Dans le second cas, nous obtenons une tache supplémentaire correspondant au I) AP' : la présence de cet acide aminé doit donc être éliminée.

B) Chromatographies circulaires : selon RutTER (1950) une première chromatographie radiale nous a permis de confirmer l'absence de I)AP : dans le système de E. Work (I955), une révélation à la ninhydrine ne nous donne pas de tache colorée en jaune, typique du DAP (fig. I7).

D'autres chromatographies ont été fait es, toujours dans le même système, en présence d'acide cystéique et de cystine (les valeurs de leurs Rf sont voisines de celles du DAP) mais sans résultats positifs (fig. I7).

Une révélation à l'isatine selon JEPson (I953) avec, comme témoins, des produits se révélant avec ce réactif (hydroxy-proline, $\beta$. alanine, acide $\alpha, \gamma$-diaminobutyriøue) reste sans résultats.

$\gamma)$ Chromatographies descendantes : les précédentes chromatographies avaient été réalisées sur papier What man $n^{\circ} \mathrm{I}$; nous avons utilisé ici du papier Arche 304 .

Xous avons vérifié que le produit brut et la fraction soluble dans le butanol, lors de l'essai de purification par le mélange butanol-eau, étaient identiques. Ces chromatogrammes ne sont pas satisfaisants, les substances forment de longues traînées ; un seul acide aminé, l'ornithine, ne semble plus être lié au reste du produit (fig. I8).

Nous avons essayé de séparer les acides aminés basiques (ou les peptides) en utilisant du phénol tamponné à pII 4 ; la présence de l'ornithine se confirme; mais si l'hydrolysat laisse apparaittre trois taches à la révélation, il reste encore accompagné de traînées rouges, bien caractéristiques des peptides : jusqu'à présent, il nous a été impossible de les scinder (fig. I9).

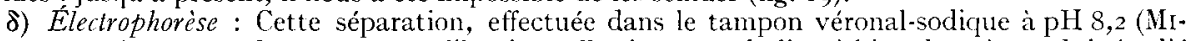
ChaELIS, I930), permet de constater qu'il existe effectivement de l'ornithine dans le produit étudié (fig. 20).

Un dosage selon VAN Slyke, modifié par Chinar1) (1952), montre que l'hydrolysat contient 0,2 p. Ioo d'ornithine.

\section{ISOLEMENT ETT IDENTIFICATION DU 24-MÉTHYLENE-CHOLESTEROL.}

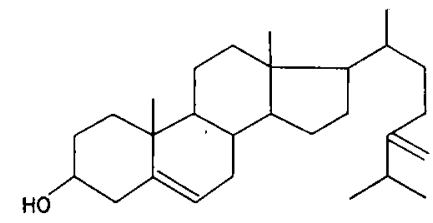

Ce stérol a été récemment isolé des abeilles par BARBIER (1959) en quantité relativement faible. Il n'a jamais été trouvé dans le règne végétal. ANDERSON (I923) avait signalé un stérol F I36,5 , mais ne l'avait pas identifié. MARIEr.AA (I952) isola les stérols ou des alcools à haut poids moléculaire mais ne poussèrent pas plus loin leurs recherches.

Nous avons trouvé ce stérol dans l'extrait alcoolique de différents pollens préalablement épuisés par l'éther. Nous avons filtré ces extraits sur colonne de silicate ; les éluats chloroforme-méthanol $95: 5$ sont traités par l'éther : la fraction insoluble contient des sucres et des acides aminés; de la fraction éthérosoluble est isolé le 24-méthylène-cholestérol. Nous l'avons retiré en premier du pollen de pommier (Pirus malus), ensuite d'un pollen mixte et enfin du pollen de Ciste (Cistus sp.). Il se trouve en quantité relativement importante (o,6 p. Ioo de l'extrait alcoolique). 


\section{DESCRIPTION DES EXPÉRIENCES}

\section{I. - Isolement à partir du pollen de pommier:}

L'extrait est filtré sur colonne de silicate de magnésium-célite $2:$ I. Dans l'essai suivant effectué sur $5 \mathrm{~g}$, on a utilisé $50 \mathrm{~g}$ d'absorbant et élué par fraction $\mathrm{de}$ I $50 \mathrm{~cm}^{3}$ :

\begin{tabular}{|c|c|c|}
\hline & onme-nucthanol $95: 5 \ldots \ldots$ & $1667 \mathrm{mg}$ \\
\hline & néthanol absolu $1: 1 \ldots \ldots \ldots \ldots \ldots \ldots$ & $193 \mathrm{mg}$ \\
\hline & ethamol absolu $\ldots . . . . . . .$. . & 1150 \\
\hline & ¿thanol-acide acctique 'ty: 1 . & \\
\hline
\end{tabular}

Les fractions $\mathrm{I}-2(1667 \mathrm{mg})$ ont été reprises cinq fois par $20 \mathrm{~cm}^{3} \mathrm{~d}$ 'éther : on sépare $\mathrm{I} 50 \mathrm{mg}$ d'insoluble et $517 \mathrm{mg}$ d'éthérosoluble. Cet éthérosoluble a été séparé en partie neutre et partie acide par le carbonate de sodium : les $517 \mathrm{mg}$ dissous dans $30 \mathrm{~cm}^{3}$ sont extraits trois fois par $10 \mathrm{~cm}^{3}$ de carbonate de sodium en solution à $5 \mathrm{p}$. r soo; la solution éthérée contenant la partie neutre est lavée deux fois par $10 \mathrm{~cm}^{3}$ d'eau puis séchée sur sulfate de sodium : on obtient $420 \mathrm{mg}$ de neutre. Après acidification par l'acide chlorhydrique $(2 \mathrm{~N})$ les acides sont extraits trois fois par $30 \mathrm{~cm}^{3}$ d'éther lavés deux fois par $10 \mathrm{~cm}^{3}$ d'eau puis séchés : on obtient $95 \mathrm{mg}$ d'acides.

La fraction neutre ainsi obtenue est chromatographiée sur $20 \mathrm{~g}$ de gel de silice; les élutions sont de $140 \mathrm{~cm}^{3}$ :
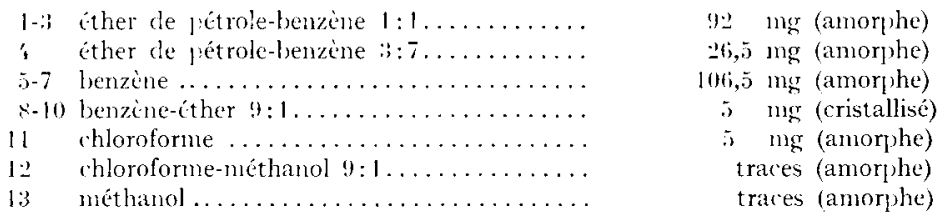

Les fractions 8-10 (106 mg) sont distillées dans un apf areil à disti.lation moléculaire. On recueille la partie distillant entre 150 et $160^{\prime \prime}$ sous $0,15 \mathrm{~mm}$ (la température est celle du bain d'huile). Le distillat, $60 \mathrm{mg}$, est cristallisé deux fois dans le méthanol ; on obtient $31 \mathrm{mg}$ de cristaux (plaques incolores) $F_{141-145^{\circ}(\alpha)}^{18}=-29^{0}$, I (chloroforme). Réaction de liebermann : blent-vert. Le spectre IR de ce stérol mesuré dans le bromure de potassium, présente deux bandes très intenses a 6 , I et I I, $3 \mu$ caractéristiques du groupement méthylène. I.'examen du spectre UV du stérol montre l'absence de dérivé 7 - déliydro conjugué dans le cycle $B$ (pas d'absorption caractéristicue entre 2 10 et $230 \mathrm{~m} \mu$ ) (fig. 2I).

Analyse élémentaire: ${ }^{1}{ }_{28} \mathrm{H}_{48} \mathrm{O}$

trouvé en pourcentage : C 84,47 II 11,7 I

calculé en pourcentage: $\mathrm{C} 84,35$ II I $1,63_{3}$.

\section{a) Ozmisation:}

Une ozonisation, effectuée sur 80 mg de stérol, en solution dans l'acide acétique, après entrainement à la vapeur d'eau, donne $26 \mathrm{mg}$ de $2-4$ dinitrophénylhydrazone de la formaldéhyde (rendement

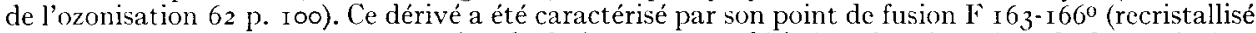
dans l'éther de pétrole), par son point de fusion avec un dérivé authentique (pas de dépression) et par chromatographie sur papier Watman $n^{0}$ r imprégné de diméthylformamide (HORNER, I955). Développement par la décaline : la technique de la chromatographie radiale a été utilisée; le $R_{\text {, }}$ du dérivé obtenu et du dérivé utilisé comme témoin est o,2 I. La présence sur le chromatogramme, d'une seule tache indique l'absence, dans le stérol isolé de dérivé 22 , ou 24-déhydro (fig. 22).

\section{b) Formation d'un acétate:}

Un acétate a été préparé à partir de I $8 \mathrm{mg}$ de ce stérol. On le dissout dans $0,4 \mathrm{~cm}^{3}$ de pyridine anhydride, on ajoute $o, 3 \mathrm{~cm}^{3}$ d'anhydride acétique et on laisse une nuit à l'étuve à $40^{\circ}$. Après avoir amené à sec, sous vide, et repris par $20 \mathrm{~cm}^{3}$ d'éther, on lave deux fois par $10 \mathrm{~cm}^{3} \mathrm{~d}^{\prime}$ acide chlorhydrique $(2 \mathrm{~N})$, une fois par $5 \mathrm{~cm}^{3}$ d'eau, puis deux fois par $10 \mathrm{~cm}^{3}$ de carbonate de sodium en solution à 5 p. 100 et enfin par $5 \mathrm{~cm}^{3}$ d'eau (deux fois). On sèche sur sulfate de sodium et l'on obtient après évaporation de la solution éthérée, 1 7,5 $\mathrm{mg}$ d'acétate brut. La cristallisation dans le méthanol fournit $9,4 \mathrm{mg}$ de cristaux (plaques incolores) $\mathrm{F}$ I $33^{-1} 35^{\circ}$. Une seconde cristallisation donne $6 \mathrm{mg}$ de produit F ${ }_{1} 34^{-1} 35^{\circ}(\alpha)_{1}^{18}=-42^{\circ}$ I (chloroforma). Le point de fusion du mélange avec un acétate authentique ne présente pas de dépression $\left({ }^{1} 35^{-1} 35,5^{\circ}\right)$. Les spectres IR (fig. 23 ) comparés des deux acétates 
sont identiques. Le spectre UV mesuré sur cet acétate ne présente aucune particularité confirmant ainsi l'absence de quantités mesurables de dérivés plus insaturés et conjugués dans le cycle B (7déhydro).

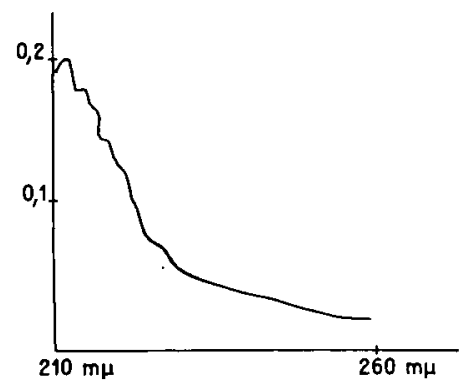

Fig. 21. - Spectre dans l'ultra violet.

acétate de 24 -méthylène-cholestérol $\left(0,156 \mathrm{mg} / \mathrm{cm}^{3}\right.$ hexane).

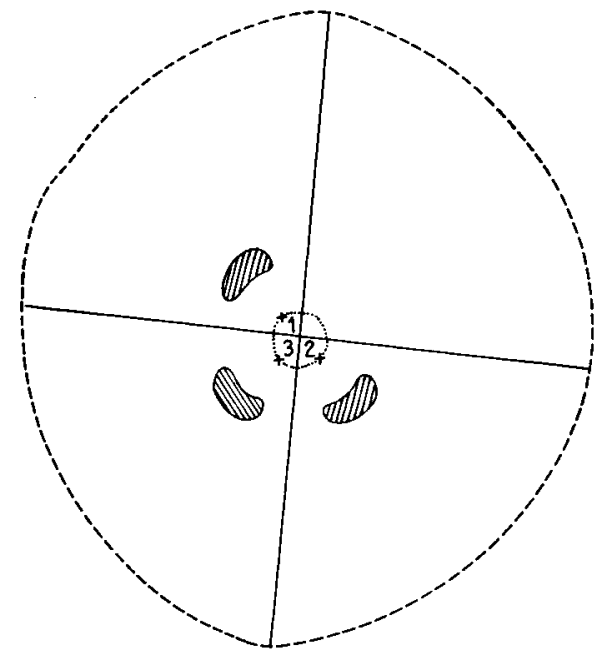

FIG. 22. - Chromalographie circulaire sur papier.

Ozonolyse du 24-méthylène cholestérol ;

solvant de développenient : décaline saturée de diméthylformamide ;

papier Whatman $n^{\circ} \mathrm{I}$ imprégné de diméthyl-formamide ;

I : témoin de 2,4-dinitrophénylhydrazone du formaldéhyde : $\mathrm{R}_{f}: 0,22$;

II : 2,4 dinitrophénylhydrazone de la substance : $\mathrm{R}_{f}: 0,22$;

III : témoin + produit : $\mathrm{R}_{f}: 0,23$.

\section{2. - Isolement à partir d'un pollen de ciste :}

Les extractions du pollen et la séparation du 24-méthylène-cholestérol sont conduites de la même manière que pour le pollen de pommier.

6,6 $\mathrm{g}$ d'éluat chloroforme : méthanol 95-5 sont traités par l'éther et fournissent $5,5 \mathrm{~g}$ de fraction soluble que l'on sépare en partie neutre et partie acide. Par chromatographie sur gel de silice, la partie neutre donne $915 \mathrm{mg}$ de stérol brut (élution benzène-éther $9: \mathrm{I}$ ) que l'on cristallise dans le méthanol ; on distille ensuite les cristaux $(230 \mathrm{mg})$. Après deux cristallisations du distillat on obtient $8 \mathrm{mg}$ de stérol pur F $137-140^{\circ}$ (plaques incolores). Réaction de Liebermann : bleu-vert. Le spectre IR présente les bandes caractéristiques à 6, i et II, $3 \mu$. 


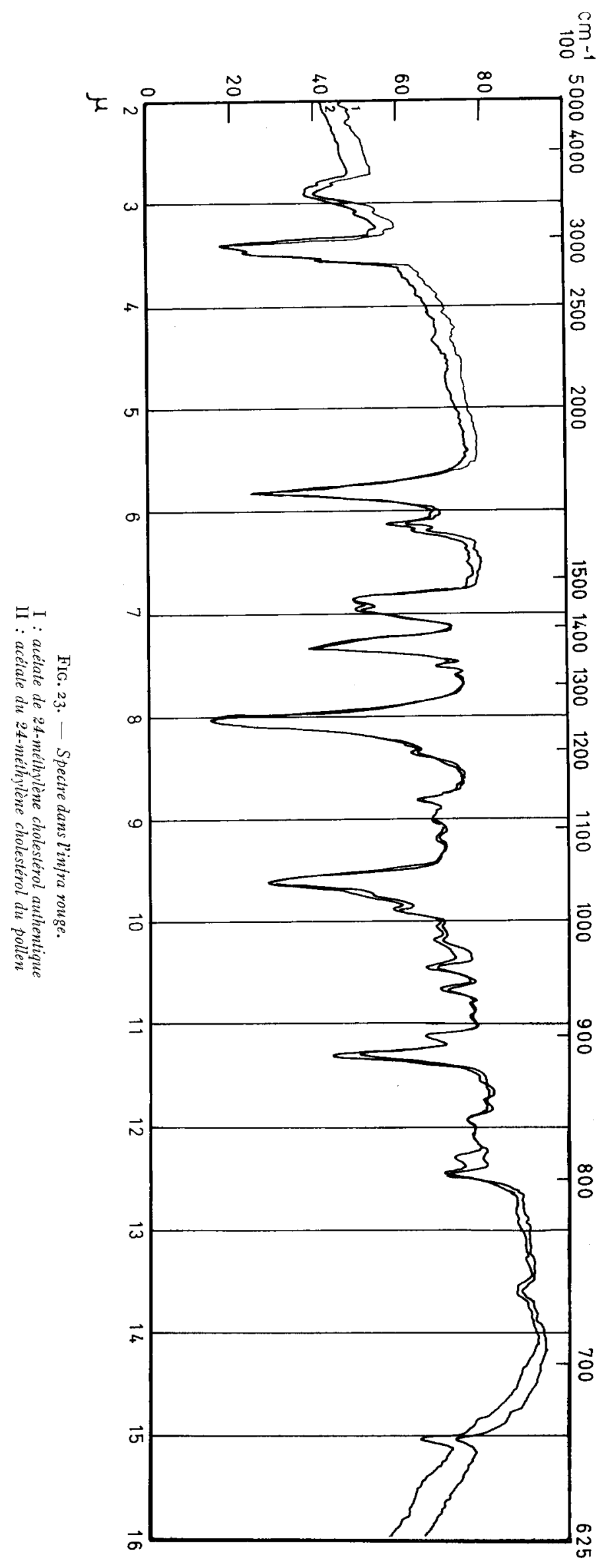




\section{Formation de l'acétale :}

Il a été préparé dans les mêmes conditions que celui isolé du pollen de pommier ; les cristaux obtenus ont un spectre IR identique à celui de l'acétate authentique $F_{\text {I }}$ I-I $35^{\circ}$. Pas de dépression du point de fusion avec l'acétate authentique.

$$
\text { 3. - Isolement à partir d'un pollen mixte: }
$$

A partir de 7,2 $\mathrm{g}$ d'éluat chloroforme-méthanol $95: 5$ nous avons obtenu 2,1 $30 \mathrm{~g}$ de fraction éthérosoluble. La séparation par le carbonate a fourni $\mathrm{I}, 7 \mathrm{~g}$ de partie neutre que l'on a chromatographiée sur gel de silice. A l'élution benzène-éther $9:$ I nous obtenons i6o $\mathrm{mg}$ de stérol brut et, après distillation, suivie de 2 cristallisations dans le méthanol- on obtient $18 \mathrm{mg}$ de cristaux (plaques incolores), $\mathrm{F}_{\mathrm{I}} 34-\mathrm{I}_{4} \mathrm{I}^{\mathrm{O}}$. Réaction de Liebermann : bleu-vert. Le spectre IR est identique à celui des stérols de pommier et de ciste.

\section{Concrusions} mixte.

Le 24-méthylène-cholestérol a été isolé de deux pollens purs et d'un pollen

ClaRk et Broch (I959) ont montré que les insectes ne peuvent effectuer la synthèse des stérols. Le 24-méthylène-cholestérol isolé des abeilles pouvait donc provenir soit de la nourriture, soit d'une transformation d'un phytostérol. Le fait d'avoir isolé le 24-méthylène-cholestérol en quantité importante de différents pollens tendrait à montrer l'origine purement alimentaire de ce stérol.

$$
\text { Reçu pour publication en janvier } 1962 .
$$

\section{REMERCIEMEN'TS}

Je tiens à marquer ma profonde gratitude à $\mathrm{Mr}$ le Pr E. LEDERER pour l'aide et les conseils qu'il m'a apportés durant toute la réalisation de ce travail.

Je remercie $M^{r}$ le $\mathrm{Pr}$ J. Dufrenoy qui m'a soutenue constamment au long de mes études au C. N.A.M.

Je remercie le $\mathrm{D}^{\mathrm{r}} \mathrm{M}$. BARBIER de l'aide et des conseils qu'il m'a donnés dans l'isolement et l'identification du 24-méthylène-cholestérol.

Les essais d'attractivité ont été effectués dans le laboratoire du Dr. R. Chauvin à Bures-surYvette par le $\mathrm{D}^{\mathrm{r}} \mathrm{J}$. Louveaux : je lui suis reconnaissante de s'être chargé de cette tâche.

Je remercie le $\mathrm{D}^{\mathrm{r}} \mathrm{R}$. IDLER pour l'échantillon d'acétate de 24 -méthylène-cholestérol qu'il a mis à ma disposition. pensable.

Je remercie Le Dr N. M. Cummings qui a fourni le pollen de Pinus montana qui m'était indis-

\section{SUMMARY}

A STUDY OF SOME OF THE COMPONENTS OF POLLEN

This paper describes various components isolated from three types of pollen and from mixed pollen. The study of most of these components must be continued.

Pine tree pollen, which is supposed to be the cause of sarcoidosis, was first investigated for similar substances to those which were isolated from Koch's bacillum lipids (mycolic acids, $\alpha, \varepsilon$-diaminopimelic acid, phosphatides). Negative results were obtained.

The method for isolating the component of pollen which attracts bees in a selective manner is described. The results show that the active part of pollen could mainly be made of a steroid, or of a mixture of steroids.

24-methylene-cholesterol, which had been isolated from oysters previously, could be isolated in large amounts and identified. It seems that bee-extracts contain large quantities of this sterol because they consume large amounts of pollen. 
I noteworthy fraction was isolated from the alcoholic extract of various types of pollen. It is insoluble in water, ether and chloroform. It is soluble in alcohol. It contains amino acids, sugars and possibly lipids. It may be a lipo-peptide or a lipo-polysaccharide.

Various substances which had never been found previously were isolated. 'They are a diol composite which is thought to be hexadecane diol-I,2 ; palmitone ; saturated carbohydrates ; fatty acids such as arachidic acid; and behenic acid esterified by cerilic alcohol. There are other substances which were only isolated and not identified (sterols of the fraction which attracts bees).

Pollen is a large source of natural product, the systematic study of which has only begun.

\section{RÉFÉRENCES BIBLIOGRAPHIQUES}

Abramsox II. A., 1947. Chemical, physical and immunological properties of electrophoretically purified pollen extracts. Ann. Allergy, 5, 1926.

Anderson, Roberts li.-G., I930. XIX Concerning the composition of phosphatide fraction isolated from the bovine type of tubercule bacillus. J. Biol. Chem., 85, $5 \mathrm{I} 9$.

Anderson J. R., ig23. Composition of com pollen. J. Biol. Chem., 55, 6r i-628.

Asselineau J., I951. Arides mycoliques et cires du bacille tuberculeux. Thèse, Paris.

Asselinfat (., Asselineau J., 1957. Sur la composition de l'huile de racine d'auncé. Bull. Soc. Chim. France, $\mathrm{I} 350$ - 1364 .

Auclair J. I., Jamikson C. A., I94s. Qualitative analysis of amino-acids in pollen collected by bees. Science, 108, 357-358.

BARBIER M., SCHINDLer O., I959. Isolierung von 2f-Methylen-cholesterin aus Künigrinnen und Arbeitcrinnen des Ilonigbiene. Helv. Chem. Acta, 42, i $998-2005$.

J3ERRY I. K., CAIN L., I949. Paper chromatographic technique for determining excretion of anino-acids in the presence of interfering substances. Arch. Biochem., 24, 179-189.

CARr F. II, Price E. A., I926. Colour reactions attributed to vitamin A. Biodchem. J., 20, 497-50 I.

Cimavis R., Defromont C., Louvearx J., Vkrgk J., I952. Sur une substance présente dans le pollen qui s'oppose au développenent de certaines bactéries. C. K. Soc. Biol, 146, 645-647.

Cireronis N. D., Entrikin J. 13., 1957. Semi-micro qualitative analysis, p. 493. Interscience Pub., NewYork.

Cinsard T. 1'., I952. T'hotometric estimation of proline and onithine. J. Biol. Chem., 199, 91-95.

CLARK A. J., BLOCH K., 1959. Conversion of ererosterol to 2 -dehydrocholesterol in Blatella germanica. J. Biol. Cihem., 234, 2589-2393.

Cummings M. M., Hubgins P. C., 1958. Chemical constituents of pine pollen and their possible rulationhip to sarcoidosis. Am. J. Med. Sci, 236, 3 г I-3 г 7 .

Demole E., t958. Applications de la microchromatographie dabsorption sur couches minces. J. Chromalography, 1, 24-34.

Discie Z., Borenfreunis E., I957. A new spray spotting of sugars on paper chromatograme. Archiv. Biochem. Bioph.,7, 239 6-240.

Esler E., Gaxzmuller J., 1930. Jie Chemische Zusammensetzung einiger Blütenstaubarten. Z. Phvsiol. Chem., 194, 2 I-23.

ERLICI P., SAcIIS F., I 890 . Ueber Condensationen von aronatischen Nitroverbindungen mit methylen Derivation. Ber, $3 \mathbf{2}, 234 \mathrm{I}-2346$.

Euler II. von, Ieller L., Hugber K. G., i 948 . Nucleoproteid aus Pollen von Birke. Ark. Ke'm. Miner. Geol., 26 A, $\mathrm{n}^{\circ} 2 \mathrm{I}$.

FeIcL F., 1954. Spot Test, 2, I I. Heverier.

Gendre T., Lederer I., HÜgfel M.-F., r956. Sur le Cord-factor". Bull. Soc. Chim. France, I478-1480.

Girard A., Sandulesco ( $i$, , I 936 . Sur une nouvelle série de réactifs du groupe carbonyle, leurs utlisations. à l'extraction de substances cétoniques et à la caractérisation microchimique des adéhydes et des cétones Heli. Chim. Acta, 19, 1095-1107.

Gordon H. T., Thornbtre W., Werty L. N., 1956. Rapid paper chromatography of carbohydrates and related compounds. Anal. Chem., 28, $849-855$.

DE. Groot A. P., I952. Amino-Acids requirements for growth of Honey-bee. Expérientia, 8, $192-193$.

Haydak M. H., Palmer I. S., i 93 s. Vitamin E content of royal jelly and bee bread. J. Econ. Entomol., 31, $576-577$.

Heyl F. W., igig. The yellow coloring substances of ragweed pollen. J. Am. Chem. Soc., 41, i $285^{-1} 289$.

Horner L., Kiruse W., i955. Studien zum Ablauf der Substitution. Liebigs Ann. Chem., 597, 48-66.

JAvillier M. 1949. Traité de Chimie organique de Grignard, 16, 853 .

Jepsos J. 13., Smith, 1953. "Multiple dipping "procedures in paper chromatography : a specific test for hydroxy-proline. Nature, 172, i ro0-I 101. 
Kumx R., Moewus F., Low T., r944. Ueber pflanzenphysiologische Spezifität von Quercetin Derivaten. Ber, 77, $219-220$.

Kuix R., Low I., I949. Ueber ein Vorkommen von milchzucker im Planzenreich. Chem. Ber., 82, $479-48 \mathrm{I}$.

Llang l', Drake N. I., Monzingo R., I94I. 'T'etranitromethane. Organic synthesis, 21, I05.

Louvedex J., I958. Recherches sur la récolte du pollen par les Abeilles. Thèse Paris.

Lunde. R., I956. Literature on pollen chemistry. Grana Palynologica (N. S.) ; 1-2, 3-2r.

Mariella R. P., Bernsteix T. B., Aoscher A. L., i953. Some purification studies on ragweed pollen. Chem. Abstracts, 47, I I 3 I.

Miciatels L., i930. Diethyl barbiturate Buffer. J. Biol. Chem., 87, 33-35.

Nakintre, G. R., Becker E. L., 1951. Phosphatases of ragweed pollen. Arch. Bioch. Biophys., 33, 78-89.

Nieisex N., Grommer J., Lunden P., i955. Chemical composition of pollen from some plants. Acta Chent. Scand., 2, 1 100-1 106.

Nilssox H., Ryinge R., Syoom Li. von, I957. Constituents of pollen. II, Longchain hydrocarbons and alcohols. Acta. Chem. Scand., 11,634-639.

Noi.t. H., Blocil H., Asselineau J., Lederer E., ig56. The chemical structure of the cord factor of Mveobaclerium luberculosis. Bioch. Bioplyys. Acta, 20, 299-309.

Okoxlki K., r95r. Coenzymes in pollen. Chem. Abstracts, 45, 304r.

PARTRIDGE S. M., I949. Aniline hydrogen phtalate as a spraying reagent for chromatography of sugars. Nithre, 164, 443 .

PESEz M., POIRIER P., 1954. Méthode de recherches en analy'se organique. 2, 220. Masson, Paris.

Pese7. M., PoIRikr P., i954. Methodes de recherches en analyse organique. 3, 40. Masson, Paris.

Pearson P. B., 1942. Panthotenic acid content of pollen. Proc. Soc. Exp. Biol. Med. 51, 815-817.

PLANTi A. von, i885. Landierirtsch. Slat. Vers., 32, 215.

Radis X. S., IAnvin I. B., Brown J. R., 1955. Colorimetric determination of cerebrosides. J. Biol. Chem., 217, $789-796$.

Ridi I. S., Aboul-Wafa M. H., 1950. Gencral composition and vitamin content of the pollen grain of th: date palm. Chem. Abstract., 44, $7492 \mathrm{a}$.

Romisson W., 1948. Delay in the apparence of palpable mammary tumeurs in $\mathrm{C}_{3}$ II mice following the

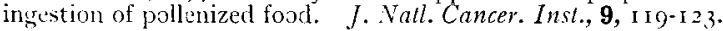

Rutier I.., 1950. Some applications of a modified in paper chromatography. Analyst, 75, 37-42.

Saxkro-Uexo I954. Sugar in pollen of corn plants. Science, 24, 90-9r.

Sek1xi, II., Li T., I950. Biological studies of pollen. Chem. Abstract, 44, $2606 d$.

Sosa-Bourdoutl C., r939. Note sur le pollen. Chem. Absiract., 33, 93604.

SosA-A., sosa-Bourdoul, C., I952. Etudes de quelques constituants chimiques du pollen de Corynus aiellana L., C.R. Acat. Sci., 235, 97 I-973.

Sosi-Botrmocit, C., Sosi 1., r954. Recherchas sur la composition du pollen de Corynus azellana L.' Bull. Soc. Chim. Biol., 36, 393-404.

Spam A., Coppini D., Monzani A., r958. Ricerce sulpolline di Cedrus deodora edi Cedrus atlantica. Ann. Chim. (Rome), 48, IsI-IS7.

Stone G. C. H., IIARkavy F., Brooks G., 1947. Chemical investigation of giant ragweed pollen. Ann. Allergy, $\mathbf{5}, 546$.

TRACEY H. V., 1950. Colorimetric determination of pentoses in presence of hexoses and uronicacids. Biochem. cle'm. J., 47, $43,3^{-4}+36$.

Virtanex A. I., Kari S., i 95.5. Acides aminés libres dans le pollen. Acla. Chem. Scand., 9, I $548 \cdot$ I 55 I.

Vivixo A. Li., Palmer L. S., i 944 . The chemical composition and nutritional value of pollens collected by bees. Arch. Bioch., 4, I $29-136$.

Weaver N., Kurken K. A., I95r. Quantitative analysis of the essential amino-acids of royal jelly and some pollens. J. Econ. Entomol., 44, 635-638.

Weychind F., Hofman H., i950. Pollinenhalstoffe. I. Mitteil. : Zucker, Pollinsäure und Ascorbinsäure. Chem. Ber., 83, 405-4I3.

Work E., 1955. The behavior of the isomers of $\alpha, \varepsilon$-diaminopinelic acid on paper chromatography. J. Am. Chem. Soc., 7ry, $4844-4846$.

Zetżcie F., Vicari H., i93i. Untersuchungen über die Membran der Sporen und Pollen (3). Helv. Chem. Acla., 14, 58-62. 